\title{
Behavior of unbonded post-tensioning monostrand anchorage systems under short duration, high amplitude cyclical loading
}

\author{
Eric Musselman $^{a e}$, Matthew Fournier $^{b}$, Patrick McAlpine ${ }^{c}$, and Sri Sritharan ${ }^{d}$
}

a) Assistant Professor, Dept. of Civil and Environmental Engineering, Villanova University

b) Graduate Student Researcher, Dept. of Civil Engineering, University of Minnesota Duluth

c) Graduate Student Researcher, Dept. of Civil and Environmental Engineering, Villanova University

d) Wilson Engineering Professor, Dept. of Civil, Construction \& Environmental Engineering, lowa State University

e) Corresponding author. Contact information:

Mail: $800 \mathrm{E}$. Lancaster Ave

139 Tolentine Hall

Villanova, PA 19085

Email: eric.muselman@villanova.edu

Phone: (610) 519-7631 


\section{Abstract}

This study evaluates the behavior of monostrand post-tensioning anchorages under both monotonic and short duration high amplitude (post-yield) cyclical loading representative of use in self-centering structural applications designed to provide seismic resistance. Anchorages from two different manufacturers were tested in coupled and uncoupled configurations. In addition, a modified wedge geometry was evaluated to determine if the performance of the system could be improved. Strain within the strand was recorded using extensometers and strain gages for different samples. A detailed evaluation of the relationship between the strain within the strand and the elongation measured by the testing frame was conducted to ensure that the strain within the strand was calculated accurately throughout the tests. The results of this research indicate that the strain within the strand is not linearly related to the elongation recorded by the testing frame, and a more accurate method was developed to allow for this conversion. Additionally, it was determined that couplers did not significantly affect the capacity of the system, but the capacity was affected by the manufacturer of the anchorage system and the loading regime used to test the sample. Based upon the observed variations in capacities, this study recommends the design of monostrand post tensioned systems using cast anchorages should be limited to a strain of $0.01 \mathrm{~mm} / \mathrm{mm}$.

\section{Keywords}

Monostrand; post-tensioning; couplers; strain capacity; post-tensioning anchorages; precast; rocking walls 


\section{Introduction}

Since the mid-1990s, seismic design of precast structures has largely relied on utilizing unbonded post-tensioning to establish the connection between precast members and the adjoining element [1][2][3]. This concept enables the precast structural systems to minimize structural damage and offer self-centering capability when they are subjected to earthquake lateral forces. Significant effort by multiple researchers has also been spent developing various design guidelines, procedures, and aids to allow for these systems to be incorporated into structures by the design engineers [4][5][6][7]. The desirable behavior and improved understanding of the design process for these precast concrete structural elements has promoted the use of unbonded post-tensioning in seismic-resistant design of structures designed with other construction materials (e.g., steel, masonry and timber). For all of these systems to perform as desired, the post-tensioning tendons should be anchored adequately and an appropriate ultimate strain limit should be established for the prestressing strands in consideration of anchorage condition. Low relaxation prestressing steel that is commonly used for prestressing self-centering structures has an ultimate strain capacity of at least 0.04 . However, such large strains would not typically be reached due to strands failing prematurely near the anchorage.

In order to establish a reliable strain limit for prestressing steel used in self-centering applications, and in coordination with previously conducted related research, the objectives of this paper are to:

- Determine the ultimate strength and strain capacity of cast monostrand posttensioned anchorages under monotonic and short duration high amplitude (postyield) cyclical loads

- Using monostrand anchorages, develop a dependable strain limit for prestressing strand for use in the design of structures with unbonded tendons 
- Determine the effect of couplers and modified wedge geometries on the ultimate strength and strain capacity of monostrand post-tensioned systems under monotonic and short duration high amplitude (post-yield) cyclical loads

- Evaluate the relationship between the elongation measured by the testing machine, anchorage seating, and elongation of the strand

This paper is focused on the first part of a two part testing program designed to evaluate the behavior of both monostrand and multistrand anchorages. While this study is focused solely on monostrand anchorages, many of the objectives result in knowledge that informs the behavior of multi-strand systems, which are more commonly used in self-centering systems. These multi-strand systems are directly evaluated in the second part of the testing program.

\section{Background}

The use of self-centering rocking wall systems has highlighted the need to better understand the behavior of unbonded post-tensioning systems. Previous research conducted by Walsh and Kumara [8] examined the monotonic and cyclical resistance of monostrand posttensioning systems. Their research focused on monostrand testing of both cast and barrel anchorages. Monotonic testing showed a wide range of failure strains ranging from 0.01 $\mathrm{mm} / \mathrm{mm}$ to $0.04 \mathrm{~mm} / \mathrm{mm}$, leading to the conclusion that design strains should be limited to 0.01 $\mathrm{mm} / \mathrm{mm}$ (1\% strain) for unbonded post-tensioning systems. Walsh and Kumara also found that cast anchors provided by the same manufacturer but with different casting date codes had significantly different capacities. Walsh and Kumara examined the accuracy of a $50 \mathrm{~mm}$ extensometer compared to a $900 \mathrm{~mm}$ extensometer as required by the International Code Council Evaluation Service (ICC-ES) [9]. They found that the $50 \mathrm{~mm}$ extensometer provided reliable results and the requirement for a $900 \mathrm{~mm}$ extensometer is not justified. 
Another method that has been evaluated in the literature for determining the strain within prestressing strand is through the use of strain gages. Strain gages are generally bonded to an individual wire of a 7-wire prestressing strand, oriented along the axis of the wire. In doing so, the strain gage measurement reflects the strain of the individual wire rather than that of the strand as a whole. Research conducted by Yates indicated that significantly different levels of strain could be observed amongst individual exterior wires at low load levels [10]. However, after a certain load is applied and each wire is fully anchored, the subsequent strain increases are relatively linear with near equivalent slopes. For this reason, Yates recommended that only strain readings corresponding to stresses higher than $345 \mathrm{MPa}$ be considered for the preparation of a linear calibration curve. However, through extensive instrumentation and testing in a later study, Acosta concluded that when all strain gages are installed at one particular cross-section and at an equal distance of at least $600 \mathrm{~mm}$ from the anchorage ends, the gages measure similar values of strain even at low stress levels [11].

In a later study, Walsh and Kumara conducted testing on anchorage systems following the procedure outlined in the ICC-ES document, as well as modified loading procedures that included post-yield cyclical loading and loading with end eccentricities [12]. They found that the post-yield cyclical loading results in reduced wire fracture strains, and that this behavior is not captured in the ICC-ES procedure as the upper stress limit for the cyclical loading is too low. As with the previous testing, $0.01 \mathrm{~mm} / \mathrm{mm}$ was recommended as the maximum design strain for unbonded post-tensioning systems. A variety of loading rates were used for the testing, with $0.056 \mathrm{~mm} / \mathrm{mm} / \mathrm{minute}$ being the maximum value. One recommendation for future research was to conduct additional tests at strain rates that are more representative of seismic applications [12].

The research described in this paper builds upon the research conducted by Walsh and Kurama to better understand the behavior of unbonded post-tensioning systems under both monotonic as well as high strain rate cyclical testing representative of use in a rocking wall 
system. Cast monostrand anchorages from two different U.S. manufacturers are examined under monotonic loads and cyclical loads simulating seismic effects. Continuous and coupled systems are examined to determine if the presence of a coupler has an effect on the capacity of the system. In addition, wedges with a modified geometry are evaluated. The standard wedge geometry is modified based upon two principles with the goal of producing a more uniform force distribution along the wedge length and allowing the strands to sustain large inelastic strains before experiencing fracture, which typically occurs at the anchor point.

The first principle used to modify the geometry is referred to as "angle differential" [13]. Standard wedges have a geometry in which the taper angle of the exterior surface of the wedge matches the taper angle of the wedge receiving bore, both of which are approximately 7 degrees. This type of wedge geometry, which is the current industry standard, forces all of the wedge teeth to engage on the strand simultaneously when loading begins [14]. Once the entire wedge length has engaged, elongation of the strand within the anchorage is significantly restrained. Thus, the load along the length of the wedge is concentrated at the nose. This socalled "elongation nose loading" begins early in the loading and propagates as loading continues. Eventually, this stress concentration causes the premature failure of an individual wire within the anchorage at the nose of the wedge.

Alternatively, the wedges in this study with a modified geometry have an exterior surface taper angle that is 1 to 2 degrees greater than that of the wedge receiving bore. This angle differential allows the wedge to grip the strand sequentially from the "back" or wide end of the wedge to the "nose" or narrow end of the wedge as load increases. This fundamental change in the engagement of wedge teeth allows elongation of the strand to occur within the wedge throughout the majority of the loading. As a result, the normal force on the strand along the length of the wedge is more balanced as the load approaches the free-length failure strength of the strand, as shown in Figure 1. 
The second principle of the modified wedge geometry is referred to as "gap control" [15]. When wedges are placed around the strand prior to loading, an initial (uncompressed) gap exists between wedge pieces. As the prestressing force increases, the wedge pieces compress laterally, closing this initial gap. If the gap between wedge pieces is allowed to close completely, the wedges are no longer able to move inward and grip the strand as load increases. Unless designed carefully, the contact of the two wedge pieces can make the system potentially susceptible to a pull-out failure in which the gripping force of the wedge is no longer sufficient to restrain the tensile force of the strand.

The wedges denoted by the name "standard" have a geometry in which the wedge pieces will remain in "free float" (i.e., will never come in contact) throughout the loading sequence. Alternatively, the modified wedge developer has determined experimentally that allowing the wedge pieces to come into contact, with reasonable limitation, is actually beneficial to the operation of the anchor system overall. Therefore, the wedges with a "modified" geometry are manufactured to have a smaller uncompressed gap between wedge pieces. When this smaller initial gap is implemented, the centering movement of the wedges is stopped late in the loading sequence due to the wedge pieces coming into contact. This allows the wedges to penetrate the exterior strand wires only enough to avoid a pull-out failure without "over-penetrating" the strand and generating stress concentrations which reduce the capacity of the system. 


\section{Experimental Program}

The experimental program is summarized in the test matrix shown in Table 1. Cast anchorages and the corresponding wedges were obtained from two different manufacturers. In addition, each manufacturer provided mechanical couplers with all of the required hardware. All wedges provided for both the anchorages and couplers were two piece wedges. As discussed in Section 2, Manufacturer 2 also produced wedges with a modified geometry, which were used with standard anchorages provided by the same manufacturer. All testing for each strand size was conducted on strand from the same spool of $1861 \mathrm{MPa}$ low relaxation prestressing strand meeting the requirements of ASTM A416 [16]. Each configuration indicated in the table had at least three samples tested. Figure 2 shows a cast anchorage, wedge and coupler as provided by Manufacturer 1 . The components provided by Manufacturer 2 were very similar. 
Table 1: Testing Program

\begin{tabular}{|c|c|c|c|c|}
\hline $\begin{array}{c}\text { Strand } \\
\text { Diameter }(\mathrm{mm})\end{array}$ & Manufacturer & $\begin{array}{c}\text { Coupler } \\
\text { Used }\end{array}$ & $\begin{array}{l}\text { Loading } \\
\text { Condition }\end{array}$ & $\begin{array}{c}\text { Instrumentation } \\
\text { Configuration }\end{array}$ \\
\hline \multirow{18}{*}{12.5} & \multirow{8}{*}{1} & \multirow{4}{*}{ No } & Monotonic & Ext., Disp. \\
\hline & & & $0.4-0.9 f_{p u}$ & Ext. \\
\hline & & & $0.4-0.95 \mathrm{f}_{\mathrm{pu}}$ & Ext. \\
\hline & & & $0.2-0.95 \mathrm{f}_{\mathrm{pu}}$ & Ext. \\
\hline & & \multirow{4}{*}{ Yes } & Monotonic & Disp. \\
\hline & & & $0.4-0.9 f_{p u}$ & Disp. \\
\hline & & & $0.4-0.95 \mathrm{f}_{\mathrm{pu}}$ & Disp. \\
\hline & & & $0.2-0.95 f_{p u}$ & Disp. \\
\hline & \multirow{8}{*}{2} & \multirow{4}{*}{ No } & Monotonic & SG, Ext., Disp. \\
\hline & & & $0.4-0.9 f_{p u}$ & Ext. \\
\hline & & & $0.4-0.95 \mathrm{f}_{\mathrm{pu}}$ & SG, Ext. \\
\hline & & & $0.2-0.95 \mathrm{f}_{\mathrm{pu}}$ & Ext. \\
\hline & & \multirow{4}{*}{ Yes } & Monotonic & Disp. \\
\hline & & & $0.4-0.9 f_{p u}$ & Ext. \\
\hline & & & $0.4-0.95 \mathrm{f}_{\mathrm{pu}}$ & Ext. \\
\hline & & & $0.2-0.95 \mathrm{f}_{\mathrm{pu}}$ & Disp. \\
\hline & 2 Modified & Nl & Monotonic & SG \\
\hline & Geometry & INO & $0.4-0.95 \mathrm{f}_{\mathrm{pu}}$ & $S G$ \\
\hline \multirow{4}{*}{15} & \multirow{2}{*}{2} & \multirow{2}{*}{ No } & Monotonic & SG \\
\hline & & & $0.4-0.95 \mathrm{f}_{\mathrm{pu}}$ & SG \\
\hline & \multirow{2}{*}{$\begin{array}{l}2 \text { Modified } \\
\text { Geometry }\end{array}$} & \multirow{2}{*}{ No } & Monotonic & $\overline{S G}$ \\
\hline & & & $0.4-0.95 \mathrm{f}_{\mathrm{pu}}$ & $S G$ \\
\hline
\end{tabular}

\subsection{Test Setup}

Testing was conducted at two different laboratories using two similar testing machines. The majority of the testing was completed at the University of Minnesota Duluth on a $245 \mathrm{kN}$ capacity servo-hydraulic computer controlled testing machine. The modified geometry specimens, some comparison specimens, and the $15 \mathrm{~mm}$ strand samples were tested at Villanova University on a $490 \mathrm{kN}$ capacity servo-hydraulic computer controlled testing machine. A steel frame was attached to both machines which enabled testing of strands with monostrand anchorages. Figure 3a shows the upper loading frame in the testing machine. The frame consisted of $50 \mathrm{~mm}$ thick top and bottom plates with a length of $200 \mathrm{~mm}$ and width of $150 \mathrm{~mm}$. 
The inside plate had a $50 \mathrm{~mm}$ diameter hole to allow the cast anchorages to sit flush against the testing plate. The sides of the frame were $18 \mathrm{~mm}$ thick steel plates with a length of $350 \mathrm{~mm}$ and width of $150 \mathrm{~mm}$, resulting in a clear spacing between the top and bottom plates of $250 \mathrm{~mm}$. Identical frames were attached to both the top and bottom of the testing machine. The holes in the inside plate were sized so that the anchorage fit tightly when inserted, ensuring alignment of the top and bottom anchorage.

The bottom frame was attached to the hydraulic cylinder which was able to rotate during the test. A cross member was attached to the testing machine to prevent the rotation caused by unwinding of the strand under loading. This condition of non-rotating end supports replicates the conditions in an actual structure where the anchorages are restrained by the friction forces acting against the element being post-tensioned. The loading frames were then positioned to produce a free length of the strand during testing of approximately $900 \mathrm{~mm}$ for the uncoupled tests. When testing couplers, two lengths of strand approximately $400 \mathrm{~mm}$ long were used. These both result in a length that is less than the $1050 \mathrm{~mm}$ recommended by the ICC-ES document [9], but was the maximum length that could be placed within the testing machines used within this study.

Once the strand was prepared, it was inserted into the test frame and wedges were placed into the anchorages. The wedges were inserted by hand and then pre-seated through the use of a hydraulic jack as shown in Figure 3b. The hydraulic jack applied load through a load cell to a steel pipe which fit around the strand and applied load directly to the wedges. A seating force of $3.56 \mathrm{kN}$ was applied based on the ICC-ES test requirement that the applied preload (seating load) should not exceed $4.45 \mathrm{kN}$ [9]. This method of pre-seating ensured that there was minimal differential seating of the wedges. Figure $3 c$ shows the anchorage, wedges and strand after seating but prior to testing.

Three different configurations of instrumentation were used to monitor the behavior of the sample during testing, as indicated in Table 1. For samples indicated by SG on Table 1, 
strain gages mounted at the mid-height of the sample to an individual wire were used to determine the representative strain within the strand. The strain gages have a gage length of 2 $\mathrm{mm}$ and were oriented along a wire at a slight angle to the vertical. In addition, linear potentiometers were used to measure the movement of the anchorage, wedge, and the relative movement of the two loading frames. These potentiometers are indicated as POT 2, POT 3, and POT 1 respectively in Figure 4a. Figure 4b shows more detail of the configuration of the potentiometers 2 and 3. A strain gage mounted on the surface of the cast anchor, labeled SG2, is also shown in Figure 4b. This gage was mounted to obtain data which will be used to calibrate a numeric simulation of the anchorage system in a future study. The data obtained did not contribute to the objectives of this study and will not be discussed. An alternate instrumentation configuration used a $25 \mathrm{~mm}$ extensometer placed at the mid-height of the strand as the primary means to determine the strain within the strand. This configuration is indicated by Ext. in Table 1. For all tests, the load and hydraulic cylinder displacement were recorded, and for a third set of samples, labeled Disp. in Table 1, this was the only data recorded. Due to the violent nature of the strand failure, both the linear potentiometers and extensometers were removed at approximately $0.9 \mathrm{f}_{\mathrm{pu}}$ to prevent damage to the instrumentation during failure, where $f_{p u}$ is the ultimate failure stress of the prestressing strand $(1161 \mathrm{MPa})$. However, as shown subsequently, the test frame displacement was used to obtain the strain in the strand once the instrumentation was removed.

\subsection{Loading Procedures}

The monotonic and cyclic loading schemes were based on the ICC-ES document discussed in Section 2 [9]. The monotonic loading protocol used a constant, displacementcontrolled load rate of $9.0 \mathrm{~mm} / \mathrm{min}$., which corresponds to a strain rate of $0.01 \mathrm{~mm} / \mathrm{mm} / \mathrm{min}$ for a $900 \mathrm{~mm}$ initial length of strand. This falls within the ICC-ES requirements of a strain rate between 0.0047 and $0.021 \mathrm{~mm} / \mathrm{mm} / \mathrm{min}$. [9]. 
The cyclic loading protocol consisted of three parts: (1) ramp to lower bound; (2) sinusoidal cyclic loading; and (3) ramp to failure. The ramp to lower bound step replicated the monotonic load rate of $9.0 \mathrm{~mm} / \mathrm{min}$ for stresses from zero to the lower limit of cyclical loads $(0.2$ $f_{p u}$ or $0.4 f_{p u}$ as indicated in Table 1). The specimen was then cycled 50 times from the lower bound to the upper bound stress (i.e. $0.9 \mathrm{f}_{\text {pu }}$ or $0.95 \mathrm{f}_{\mathrm{pu}}$ ). All samples were tested at the maximum loading rate at which the testing machine was capable. For the testing completed at the University of Minnesota Duluth, this was at a frequency of $2 \mathrm{Hertz}$, and for the testing completed at Villanova this was 0.5 Hertz. Several deviations from the ICC-ES document were required for this loading step due to limitations of the testing equipment and the anchorage capacities. The ICC-ES document calls for a cycle frequency between 1 and 3 hertz and a cyclic stress range between $0.40 \mathrm{f}_{\mathrm{pu}}$ and $0.85 \mathrm{f}_{\mathrm{pu}}$. However, previous research by Walsh and Kurama [12] indicated that little reduction in capacity was seen below the yield stress when a cyclic frequency of less than $1 \mathrm{~Hz}$ is used. Therefore, the higher limits of 0.9 and $0.95 \mathrm{f}_{\mathrm{pu}}$ were used in this research program. Upon completion of 50 cycles, the specimen was pulled to failure at a constant, displacement-controlled load rate of $9.0 \mathrm{~mm} / \mathrm{min}$, again replicating the monotonic loading rate. This loading regime is summarized in Figure 5.

The cyclic loading requirement in the ICC-ES document is intended for fatigue not for seismic load tests. Testing conducted in another phase of this research program evaluated the behavior of rocking precast concrete walls and found that the corresponding prototype wall will have a dominant response at a frequency of $0.35 \mathrm{~Hz}$. Depending on the aspect ratio of the rocking structural member, their dominant frequency can vary significantly when subjected to a seismic input motion. The wall tests further confirmed that the strain rate in the unbonded tendon varies at the same frequency as the rocking member. While this frequency is outside the recommended frequency range for fatigue testing in the ICC-ES document, the two frequencies used in the tests provided adequate variations in the loading rate and represent structures with different aspect ratios. The typical stress range in the strand during these tests 
was approximately $0.4 \mathrm{f}_{\mathrm{pu}}$ to $0.95 \mathrm{f}_{\mathrm{pu}}$, providing further justification for the stress ranges used during the cyclic testing conducted in this study [17].

\section{Results}

The primary results of the test program are described in Table 2 for the $12.5 \mathrm{~mm}$ strand and Table 3 for the $15 \mathrm{~mm}$ strand. Included in the tables are the average ultimate strain and ultimate stress for each configuration. Each value is the average of three to six separate test results, with the exception of the Manufacturer 1 coupled system exposed to ramp or monotonic loading, which only consists of 2 samples as one did not return useable data. The failure stress for each sample was obtained by dividing the failure load by the cross-sectional area of strand as indicated on the mill certifications received with the strand. The calculation of the failure strain will be discussed in Section 4.1

In addition to the failure strain and stress, Tables 2 and 3 contain the results of a twotailed Student's t-test. The t-tests were used to evaluate the null hypothesis of equivalent means for the loading scheme, anchorage manufacturer, coupler presence, and wedge geometry variables. For all tests, it was assumed that the two populations are unpaired and have about the same spread (i.e., they are homoscedastic). A small t-test result indicates a high likelihood that the compared data sets are statically different. The comparisons highlighted in Tables 2 and 3 are t-tests with values below 0.05, which indicates there is a $95 \%$ likelihood that the data sets have different means. The t-test results presented are based on the results of the measured failure stress of the strand; similar results were achieved when evaluating the failure strain. For Table 2, the first t-test column compares coupled to uncoupled systems and standard to modified geometry wedges. The second column compares the two manufacturers and the third compares the loading types to the ramp loading results. The columns in Table 3 
compare standard to modified geometry wedges and monotonic to cyclical loadings, respectively.

Table 2: Results for $12.5 \mathrm{~mm}$ strand

\begin{tabular}{|c|c|c|c|c|c|c|c|}
\hline Load Type & Manufacturer & $\begin{array}{l}\text { Testing } \\
\text { Location }\end{array}$ & $\begin{array}{c}\text { Failure } \\
\text { Strain } \\
(\%)\end{array}$ & $\begin{array}{l}\text { Failure } \\
\text { Stress } \\
\text { (MPa) }\end{array}$ & $\begin{array}{c}\text { T-Test } \\
\text { (Level } \\
1)\end{array}$ & $\begin{array}{c}\text { T- Test } \\
\text { (Manuf.) }\end{array}$ & $\begin{array}{l}\text { T-Test } \\
\text { (vs. } \\
\text { Ramp) }\end{array}$ \\
\hline \multirow{6}{*}{ Monotonic } & 1 & UMD & 3.05 & 1828 & \multirow{2}{*}{0.32} & \multirow{6}{*}{0.00} & \multirow{6}{*}{ NA } \\
\hline & 1 coupled & UMD & 3.21 & 1838 & & & \\
\hline & 2 & UMD & 2.18 & 1766 & \multirow{2}{*}{0.25} & & \\
\hline & 2 coupled & UMD & 2.48 & 1798 & & & \\
\hline & 2 & Villanova & 2.66 & 1805 & \multirow{2}{*}{0.48} & & \\
\hline & 2 modified & Villanova & 2.84 & 1821 & & & \\
\hline \multirow{4}{*}{$\begin{array}{c}\text { Cyclic } \\
\left(0.4-0.9 f_{p u}\right)\end{array}$} & 1 & UMD & 2.37 & 1795 & \multirow{2}{*}{0.79} & \multirow{4}{*}{0.66} & \multirow{2}{*}{0.01} \\
\hline & 1 coupled & UMD & 2.58 & 1788 & & & \\
\hline & 2 & UMD & 2.39 & 1774 & & & \multirow{2}{*}{0.61} \\
\hline & 2 coupled & UMD & 2.00 & 1784 & 0.92 & & \\
\hline \multirow{6}{*}{$\begin{array}{c}\text { Cyclic } \\
(0.4-0.95 \\
\left.f_{\text {pu }}\right)\end{array}$} & 1 & UMD & 2.83 & 1809 & \multirow{2}{*}{0.79} & \multirow{6}{*}{0.00} & \multirow{2}{*}{0.01} \\
\hline & 1 coupled & UMD & 2.76 & 1805 & & & \\
\hline & 2 & UMD & 2.35 & 1774 & \multirow{2}{*}{0.65} & & \multirow{2}{*}{0.73} \\
\hline & 2 coupled & UMD & 2.00 & 1768 & & & \\
\hline & 2 & Villanova & 2.66 & 1762 & \multirow{2}{*}{0.82} & & \multirow{2}{*}{0.01} \\
\hline & 2 modified & Villanova & 1.49 & 1755 & & & \\
\hline \multirow{4}{*}{$\begin{array}{c}\text { Cyclic } \\
(0.2-0.95 \\
\left.f_{p u}\right)\end{array}$} & 1 & UMD & 2.66 & 1810 & \multirow{2}{*}{0.83} & \multirow{4}{*}{0.06} & \multirow{2}{*}{0.04} \\
\hline & 1 coupled & UMD & 2.92 & 1813 & & & \\
\hline & 2 & UMD & 2.47 & 1789 & \multirow{2}{*}{0.98} & & \multirow{2}{*}{0.45} \\
\hline & 2 coupled & UMD & 2.48 & 1790 & & & \\
\hline
\end{tabular}

Table 3: Results for $15 \mathrm{~mm}$ strand

\begin{tabular}{|c|c|c|c|c|c|c|}
\hline $\begin{array}{c}\text { Load } \\
\text { Type }\end{array}$ & Manufacturer & $\begin{array}{c}\text { Testing } \\
\text { Location }\end{array}$ & $\begin{array}{c}\text { Failure } \\
\text { Strain } \\
(\%)\end{array}$ & $\begin{array}{c}\text { Failure } \\
\text { Stress } \\
(\mathbf{M P a})\end{array}$ & $\begin{array}{c}\text { T-Test } \\
\text { (Std. vs. } \\
\text { Mod.) }\end{array}$ & $\begin{array}{c}\text { T-Test } \\
\text { (vs. Ramp) }\end{array}$ \\
\hline \multirow{2}{*}{ Monotonic } & 2 & Villanova & 2.61 & 1891 & 0.66 & NA \\
\cline { 2 - 5 } & 2 modified & Villanova & 3.02 & 1908 & 0.66 & 0.33 \\
\hline $\begin{array}{c}\text { Cyclic } \\
(0.4-0.95 \\
\left.f_{p u}\right)\end{array}$ & 2 & Villanova & 2.46 & 1858 & \multirow{2}{*}{0.10} & 0.81 \\
\cline { 2 - 5 } & 2 modified & Villanova & 3.51 & 1917 & & \\
\cline { 5 - 7 }
\end{tabular}




\subsection{Relationship Between Strain and Displacement}

As discussed in Section 3.1, three different sources were used to obtain information about the strain in the strand. Some samples were instrumented with strain gages, which typically provided strain data up to the point of failure. Some samples had extensometers attached at mid-height until they reached a stress value approximately $0.9 \mathrm{f}_{\mathrm{pu}}$. The movement of the hydraulic cylinder within the testing machine was also recorded for all samples, and one objective of the study was to determine a relationship between this displacement and the strain within the strand. To achieve this objective, the movement of the anchorage and the wedge during testing was recorded for select samples using POT 2 and 3 shown in Figure 4. The difference in these two readings provide the seating of the wedge into the anchor. The results are shown in Figure 4 for six different $12.5 \mathrm{~mm}$ samples. The results show a fairly linear relationship between wedge seating and stress for levels between $300 \mathrm{MPa}$ and $1500 \mathrm{MPa}$. Prior to reaching $300 \mathrm{MPa}$, the wedge displacement is greater for a given change in load, as indicated by the lower slope in Figure 6 . This is likely due to the initial penetration of the teeth into the strand. Though there is less data, above $1500 \mathrm{MPa}$ the slope in Figure 6 again appears to decrease. This is attributed to a decrease in stiffness of the strand resulting in increased rate of reduction in the diameter due to Poisson's effect. The decrease in diameter allows the wedges to seat more for a given load. This result is important to the relationship between frame displacement and strain within the strand because the movement of the wedges into the anchor increases the displacement of the testing frame without contributing to the elongation of the strand.

Based upon this understanding, Equation 1 was proposed as a method to convert frame displacement to strain within the strand. In this equation, $\varepsilon_{\text {frame }}$ is calculated by dividing the displacement of the frame by the free length of the strand. The resulting curve is then shifted so that the line passing through the curve at 345 and $1380 \mathrm{MPa}$ extends through the origin. 
Variables $\sigma$ and $\varepsilon_{\text {strand }}$ are the stress and strain within the strand, and $\mathrm{K}$ was assumed to be constant. To evaluate this relationship, $\mathrm{K}$ was calculated for the samples which had either strain gages or extensometers attached. The resulting value was then plotted versus stress, and is shown in Figures 7 and 8 . Figure 7 shows the results for the same six $12.5 \mathrm{~mm}$ samples shown in Figure 6, as well as the average $\mathrm{K}$ value at each stress level. Figure 8 shows the average $\mathrm{K}$ values obtained for the $12.5 \mathrm{~mm}$ samples instrumented with strain gages, the $12.5 \mathrm{~mm}$ samples instrumented with extensometers and the $15 \mathrm{~mm}$ samples instrumented with strain gages. All strands and instrumentation methods seem to indicate similar behavior. Only the samples loaded under ramp loading conditions are shown in these figures.

$$
\varepsilon_{\text {strand }}=\varepsilon_{\text {frame }}-K \times \sigma
$$

The data shown in Figures 7 and 8 seem to indicate that the $\mathrm{K}$ factor is relatively constant, up to a load of approximately $90 \%$ of the free length fracture strength of the strands. At this point the $\mathrm{K}$ factor rapidly increases, indicating that a smaller proportion of the displacement occurring within the systems is actually causing elongation of the strand. The change in behavior and the increase in $\mathrm{K}$ factor corresponds to the transition from elastic to inelastic behavior, meaning that the strand will elongate significantly more for a given increase in load. This elongation also contributes to a reduction in the diameter of the strand due to Poisson's effects. While it is difficult to conclude with certainty because all instrumentation other than the strain gage has been removed at this point, the reduction in strand diameter may allow for the movement of the wedges into the anchor to occur at a greater rate relative to the change in load than was previously occurring within the system. This increase in anchor seating could have contributed to the increase in the $\mathrm{K}$ factor.

To account for this increase, as well as to incorporate the variation in initial $\mathrm{K}$ factor values that occur within the systems, the following relationships were used to determine $\mathrm{K}$ : 


$$
K_{o}=\frac{1}{m}-\frac{1}{E_{S}}
$$

For $\sigma \leq 0.9 \mathrm{f}_{\mathrm{fff}}$ :

$$
K=K_{o}
$$

For $\sigma>0.9 \mathrm{f}_{\mathrm{fff}}$ :

$$
K=K_{o}+0.032 \times \sigma-0.9 f_{f l f}
$$

Where:

$\mathrm{f}_{\mathrm{fff}}=$ free length fracture stress of the strand $(\mathrm{MPa})$

$E_{s}=$ modulus of elasticity of the strand $(\mathrm{MPa})$

$\mathrm{m}=$ slope of the line passing through the points at $345 \mathrm{MPa}$ and $1380 \mathrm{MPa}$ on the stress strain curve calculated from the frame displacement (MPa)

The result of these equations for both the $12.5 \mathrm{~mm}$ and $15 \mathrm{~mm}$ strands are shown by the dashed lines in Figure 8.

The procedure was used to calculate the failure strain for all samples testing in this research program. When these values were compared to the failure strain obtained from the strain gages on the samples where this information was available, the average difference between the failure strains was 0.0014 strain. Figure 9 shows a typical plot of the stress-strain curves obtained using the strain gage, Equations 2-4, and assuming a constant $\mathrm{K}$ value.

For samples instrumented with extensometers, the standard procedure is to use the extensometer data as the strain in the strand until it is removed at approximately $0.9 \mathrm{f}_{\mathrm{pu}}$, and then use an adjusted frame displacement to obtain the remainder of the strain. Assuming that the frame displacement was calculated using the initial relationship between frame displacement and strain (represented by $\mathrm{K}_{\mathrm{o}}$ in this formulation) significant error can occur in the estimation of the failure strain. The strain for each sample within this study was also calculated using a constant $\mathrm{K}$ factor and was found to produce failure strains that were 0.006 strain on 
average above the failure strain calculated using Equations 2-4. The maximum difference was 0.0092 strain.

\subsection{Effect of Couplers}

As shown in Figure 10 and indicated by the high t-test values in Table 2, couplers do not appear to have an adverse effect on the strength or strain capacity of the systems. This finding was independent of the manufacturer or type of load. This result also validated the physical results of the tests as no failure occurred at the location of the coupler; all failure occurred at either the top or bottom cast anchorage. Therefore, all results presented and the t-tests conducted to evaluate the effects of loading type and manufacturer treat coupled and uncoupled systems as equivalent.

\subsection{Manufacturer and Geometric Effects}

Figure 11 shows the results of the tests on $12.5 \mathrm{~mm}$ strand separated by manufacturer as well as wedge geometry. Examining wedge geometry from both Figure 11 and the t-tests of Table 2, it appears that wedge geometry did not significantly affect the behavior of the wedges. However, the sample size conducted in this study was small and it is difficult to make realistic predictions based on this data. A much larger data set is available when comparing performance based on Manufacturer and both Figure 11 and the majority of the t-tests in Table 2 indicate there is a significant difference between manufacturers, with Manufacturer 1 exhibiting better performance. No notable differences were observable within the geometry of the anchorages or wedges from each of the manufacturers, so the reasons for the difference are unclear. Previous research [8] has observed variations in capacity in different date stamps from the same manufacturer and attributed the difference to the metallurgy of the anchor.

Figure 12 shows the results from the much smaller testing program conducted on $15 \mathrm{~mm}$ strand. Only wedges from Manufacturer 2 were examined, including both standard and 
modified wedge geometries. The data (including the t-tests from Table 3) indicate that the modified wedge geometries may improve the performance of the system, though significant variations exist within the data. Therefore, a further refinement to the wedge geometry is deemed necessary to develop the full capacity of strands.

\subsection{Effect of Loading}

The effect of the loading scheme on the capacity of Manufacturer 1's anchorages is shown in Figure 13, and the result for Manufacturer 2's anchorages is shown in Figure 14. The t-test results from the rightmost column in Table 1 also pertain to the effect of loading scheme. The data indicates that the systems from Manufacturer 1 saw a decrease in performance when subjected to post-yield cyclical loads. The decrease does not appear to be significantly affected by the stress range of the cycles as long as the maximum value is sufficient to cause plastic deformation. The strain capacity of the system for Manufacturer 1 was reduced from $3.05 \%$ to $2.37 \%-2.83 \%$ depending on the strain range for the uncoupled system.

However, the results do not show the same trend for the results from Manufacturer 2, where the capacity did not vary based upon the loading scheme. Many of the higher capacities in Figure 14 are for samples exposed to a monotonic load; however, there were also samples loaded monotonically that had a significantly reduced capacity. Considering the higher capacity

of the Manufacturer 1 system, this result may indicate that the higher capacity systems are more susceptible to a reduction in capacity by exposure to post-yield cyclical loads.

\subsection{Design Strain Limit}

Statistical data for the failure strains of the strands is shown in Table 4. It is clear that for the samples evaluated in this project, the $12.5 \mathrm{~mm}$ strands exhibited lower failure strains than the $15 \mathrm{~mm}$ strands. Due to the larger sample size, and to be conservative, the data obtained from the $12.5 \mathrm{~mm}$ strands is used to evaluate the design strain limit for monostrand post- 
tensioned systems with cast anchorages. The cumulative distribution function for these 64 samples is plotted in Figure 15, as well as the cumulative distribution function for the mean and standard deviation assuming a normal distribution.

Table 4: Statistical Data for Failure Strains $(\mathrm{mm} / \mathrm{mm})$

\begin{tabular}{|c|c|c|}
\hline & $\mathbf{1 2 . 5} \mathbf{~ m m}$ Strand & $\mathbf{1 5} \mathbf{~ m m ~ S t r a n d}$ \\
\hline \# Samples & 64 & 12 \\
\hline Minimum Strain & 0.011 & 0.017 \\
\hline Mean Strain & 0.025 & 0.029 \\
\hline Maximum Strain & 0.033 & 0.042 \\
\hline Standard Deviation & 0.005 & 0.008 \\
\hline
\end{tabular}

The results of the experiment, especially at the lower strain values, match very well with the assumed normal distribution. Both indicate that a strain limit of $0.01 \mathrm{~mm} / \mathrm{mm}$ provides a very low $(<1 \%)$ probability of failure. If the strain limit was set at $0.015 \mathrm{~mm} / \mathrm{mm}$, the probability of failure increases to approximately $3 \%$. This information could be used by the designer of a rocking wall system to assess the strain limit that should be used for their structure based on the redundancy in the system and the probability of loading equal to the design load occurring.

\section{Conclusions and Recommendations}

This paper described an experimental research program that evaluated the performance of coupled and uncoupled monostrand post-tensioning systems under both monotonic and cyclic loading. The following conclusions can be drawn based on the 76 samples tested in this research program:

- To accurately calculate the failure strain in a system with cast monostrand anchorages Equations 1-4 should be used to convert the frame displacement to strain in the strand. Assuming only a linear relationship between frame displacement and strain in the strand can result in a significant overestimation of failure strains 
- The presence of couplers does not affect the capacity of monostrand post-tensioning systems

- Significant variation in failure stresses and strains can exist between manufacturers

- Post-yield cyclical behavior tends to reduce the capacity (both strength and strain) of some monostrand post-tensioning systems. Anchorages which have higher failure stress and strain under monotonic loads appear to be more susceptible to a reduction in capacity

- The design of monostrand post tensioned systems using cast anchorages should be limited to a strain of $0.01 \mathrm{~mm} / \mathrm{mm}$ as suggested in previous studies in order to limit strand failures. Based upon the data obtained in this study, the probability of failure would be approximately $0.2 \%$ for a strain limit of $0.01 \mathrm{~mm} / \mathrm{mm}$. A strain limit of $0.015 \mathrm{~mm} / \mathrm{mm}$ may be used if a higher (approximately $3 \%$ ) probability of failure is acceptable in the design

It should be noted that these conclusions are based only on the data collected in this study, which constitutes a relatively small data set. Based upon the information obtained in this study, it is recommended that additional research be conducted to:

- Evaluate the behavior of multi-strand post-tensioning anchorages under post-yield cyclical loading

- Further refine the wedge geometry to improve the capacity of anchorage systems

- Validate the relationship developed between frame displacement and strain in the strand in other testing machines and with extensometer data through failure. The literature has shown that strain gages provide an accurate representation of the strain within the strand; however the industry standard is to use extensometers and therefore the relationship should be validated against extensometers. 


\section{Acknowledgements}

The authors would like to thank the National Science Foundation for providing the financial support to complete the research summarized in this paper through CMMI Grant No: 1041650. Any opinions, findings, and conclusions or recommendations expressed in this material are those of the authors and do not necessarily reflect the views of the National Science Foundation.

\section{References}

[1] Nakaki, S. D., Stanton, J. F., and Sritharan S. "An overview of the PRESSS five-story precast test building." PCI Journal, v44 n2, pp. 26-39, 1999.

[2] Priestley, M. J. N., Sritharan, S., Conley, J. R., and Pampanin, S. "Preliminary results and conclusions from the PRESSS five-story precast concrete test building." PCI Journal, v44 n6, pp. 42-67, 1999.

[3] Sritharan, S., Aaleti, S., Henry, R. S., Liu, K.-Y., Tsai, K.-C. "Precast concrete wall with end columns (PreWEC) for earthquake resistant design." Earthquake Engineering \& Structural Dynamics, DOI: 10.1002/eqe.2576, 2015.

[4] Stanton, J. F., and Nakaki, S. D. "Design guidelines for precast concrete seismic structural systems." PRESSS Report No. 01/03-09, PCI, Chicago, IL, and University of Washington Report No. SM 02-02, Seattle, WA, 2002.

[5] Hawileh, R.A., Tabatabai, H., Rahman, A., and Amro, A. "Non-Dimensional Design Procedures for Precast, Prestressed Concrete Hybrid Frames." PCI Journal, v51 n6, pp.110130.

[6] Saqan, E. I., and Hawileh, R. A. "Non-dimensional design charts for unbonded posttensioned split precast concrete walls." PCl Journal, v 55 n4, pp. 78-99, 2006.

[7] Hawileh, R., Saqan, E., and Abdalla, J.A. "Simplified Optimum Design Procedure for Special 
Unbonded Post-Tensioned Split Precast Shear Walls." Journal of Structural Engineering, Technical Note, American Society of Civil Engineers (ASCE), Vol. 139, No. 2, pp. 294-299, 2013.

[8] Walsh, Kevin Q. and Kuramam, Yahya C. "Behavior of unbonded post-tensioning monostrand anchorage systems under monotonic tensile loading." PCl Journal, v 55 n1, pp 97117, 2010.

[9] ICC-ES. Acceptance Criteria for Post-Tensioned Anchorages and Couplers of Prestressed Concrete. Evaluation Report AC303, Whittier: International Code Council Evaluation Service. 2007.

[10] Yates, D. L. A Study of Fretting Fatigue in Post-Tensioned Concrete Beams. M.S. Thesis, Austin, TX: The University of Texas at Austin, 1988.

[11] Acosta, Jose Antonio Arrellaga. Instrumentation Systems for Post-Tensioned Segmental Box Girder Bridges. Master's Thesis, Austin: University of Texas at Austin, 1991.

[12] Walsh, Kevin Q. and Kurama, Yahya C. "Effects of loading conditions on the behavior of unbonded post-tensioning strand-anchorage systems." PCl Journal, v 57 n1, pp. 76-96, 2012. [13] Hayes, Norris O., and Randy Draginis. Anchor System with Substantially Longitudinally Equal Wedge Compression. United States of America Patent 7,765,752 B2. August 3, 2010. [14] Walsh, K.Q., Draginis, R.L., Estes, R.M., Kurama, Y.C. "Effects of Anchor Wedge Dimensional Parameters on Post-Tensioning Strand Performance," Report\#NDSE-2013-02, 2013.

[15] Hayes, Norris O., and Randy Draginis. Anchor Wedge Configuration for Tendon Anchors. United States of America Patent 7,726,082 B2. June 1, 2010.

[16] ASTM Standard A416, 2012a. "Standard Specification for Steel Strand, Uncoated SevenWire for Prestressed Concrete." ASTM International, West Conshohocken, PA. 2012. 
[17] Nazari, M., Sritharan S., and Aaleti, S. "An Experimental Evaluation of Unbonded PostTensioned Precast Rocking Walls." In Proceedings of the 60th PCI Convention and National Bridge Conference, Washington, DC, September 2014. 


\section{Figure Captions}

Figure 1: Load distribution within wedge due to angle differential principle

Figure 2: Components provided by Manufacturer 1

Figure 3: Top loading frame and seating procedure used for wedges

Figure 4: Test setup including instrumentation locations

Figure 5: Cyclical loading procedure

Figure 6: Wedge seating for $12.5 \mathrm{~mm}$ wedges (standard and modified geometry)

Figure 7: Adjustment factor, $\mathrm{K}$, for $12.5 \mathrm{~mm}$ strand monitored with strain gages

Figure 8: Average adjustment factor, $\mathrm{K}$

Figure 9: Comparison of strain gage readings and calculated strain for a $12.5 \mathrm{~mm}$ sample

Figure 10: Fracture stress and strain for coupled versus uncoupled systems (12.5 mm strand)

Figure 11: Fracture stress and strain for various Manufacturers (12.5 mm)

Figure 12: Fracture stress and strain for Manufacturer $2(15 \mathrm{~mm})$

Figure 13: Fracture stress and strain for Manufacturer $1(12.5 \mathrm{~mm})$

Figure 14: Fracture stress and strain for Manufacturer $2(12.5 \mathrm{~mm})$

Figure 15: Cumulative Distribution of Failure Strain for $12.5 \mathrm{~mm}$ Strand 
Wedge Mechanism
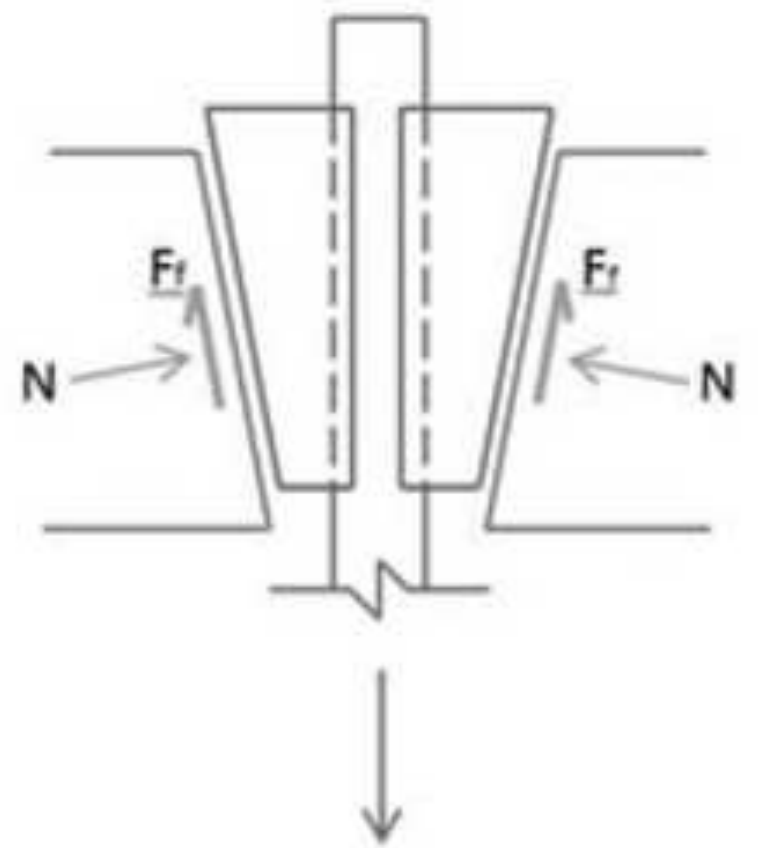

$0.10 f_{p u}$
Standard Wedge

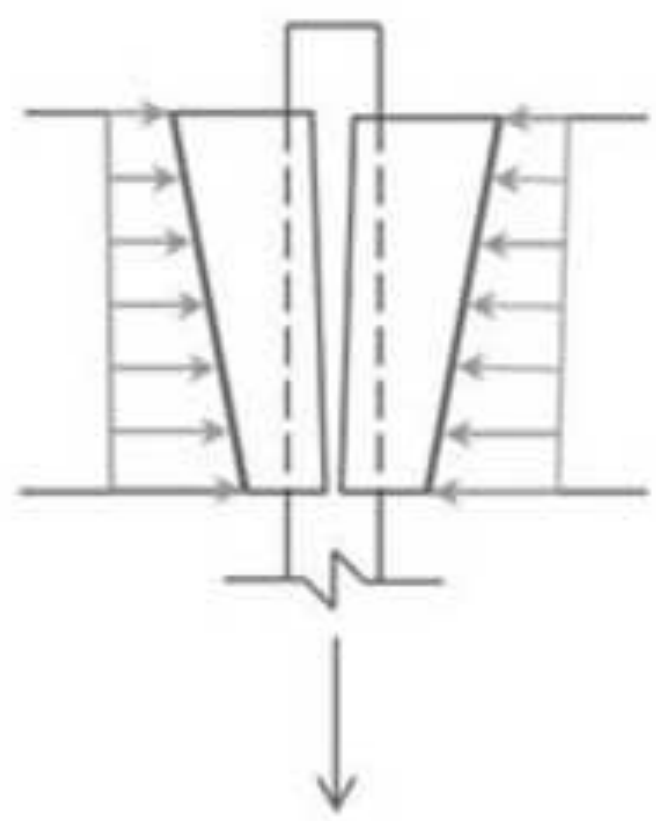

$0.95 f_{p u}$
Modified Wedge

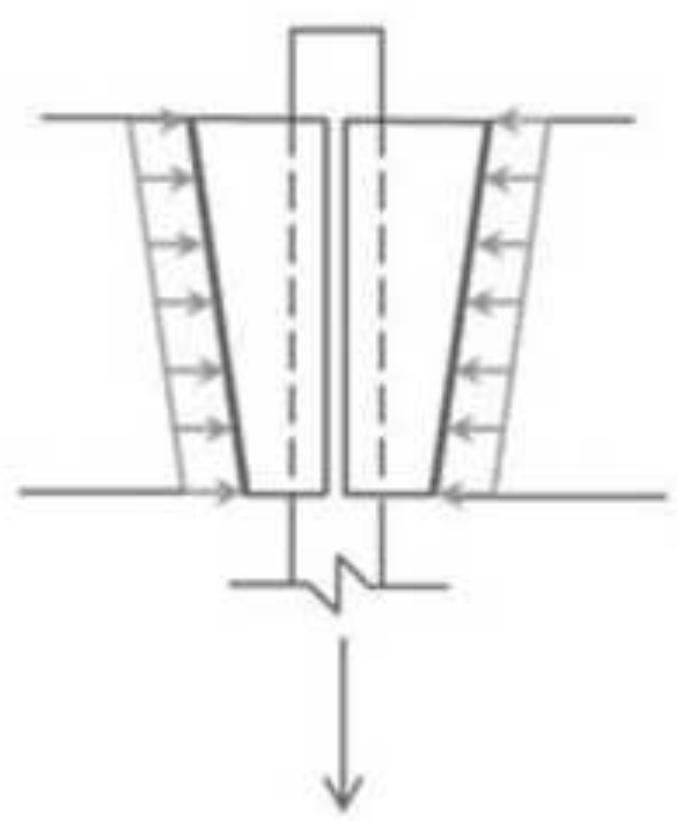

$0.95 f_{p u}$ 
Wedge Mechanism

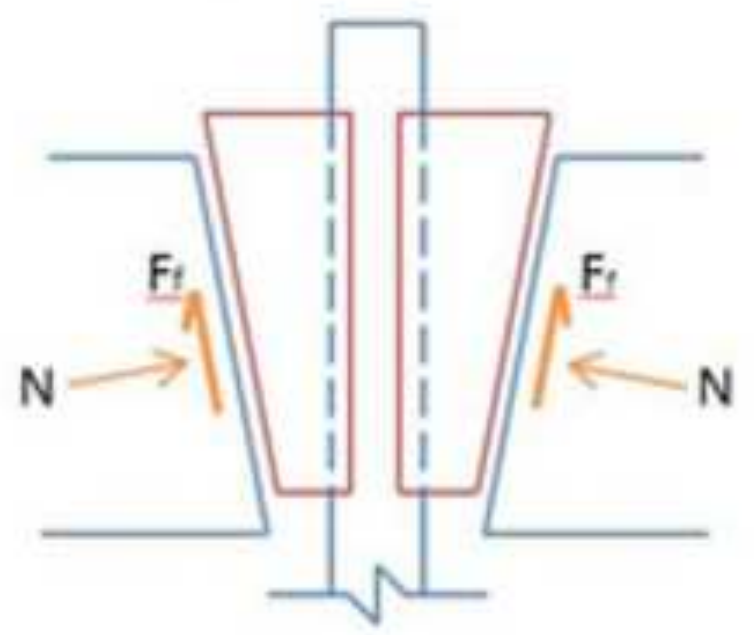

$0.10 f_{p u}$

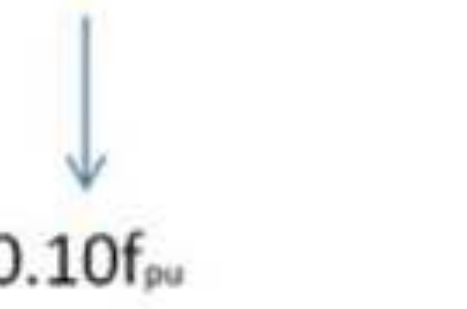

Standard Wedge

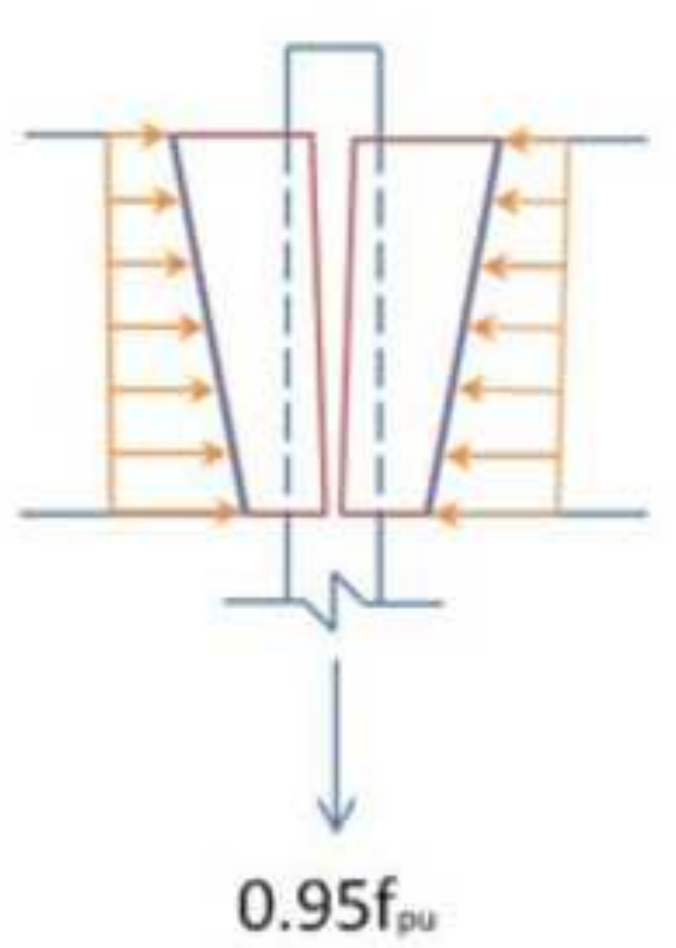

$0.95 f_{p u}$
Modified Wedge

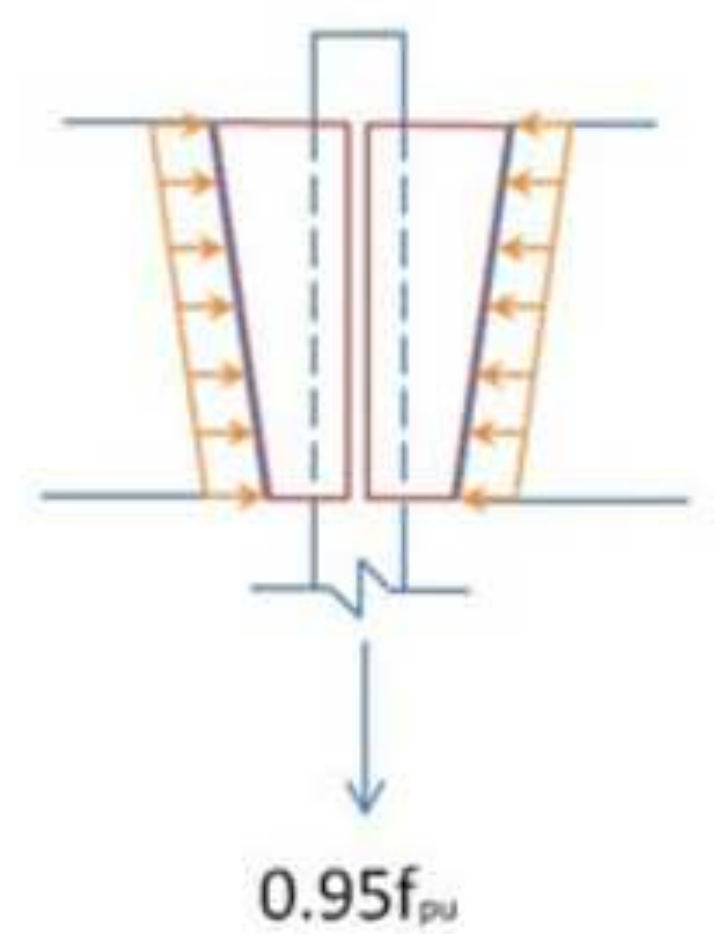

$0.95 f_{p u}$ 
a) Cast anchorage

a) Cast anchorage

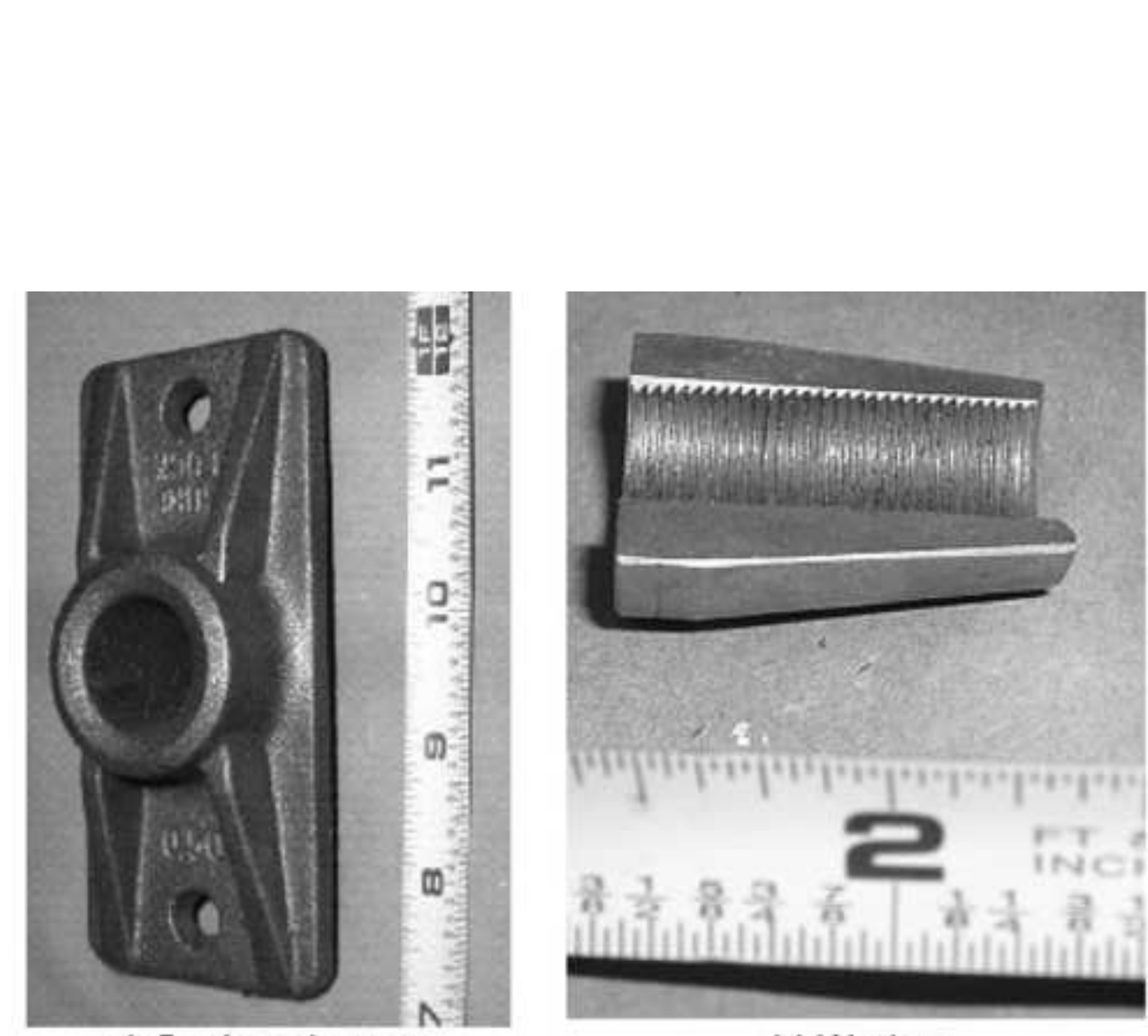

b) Wedge

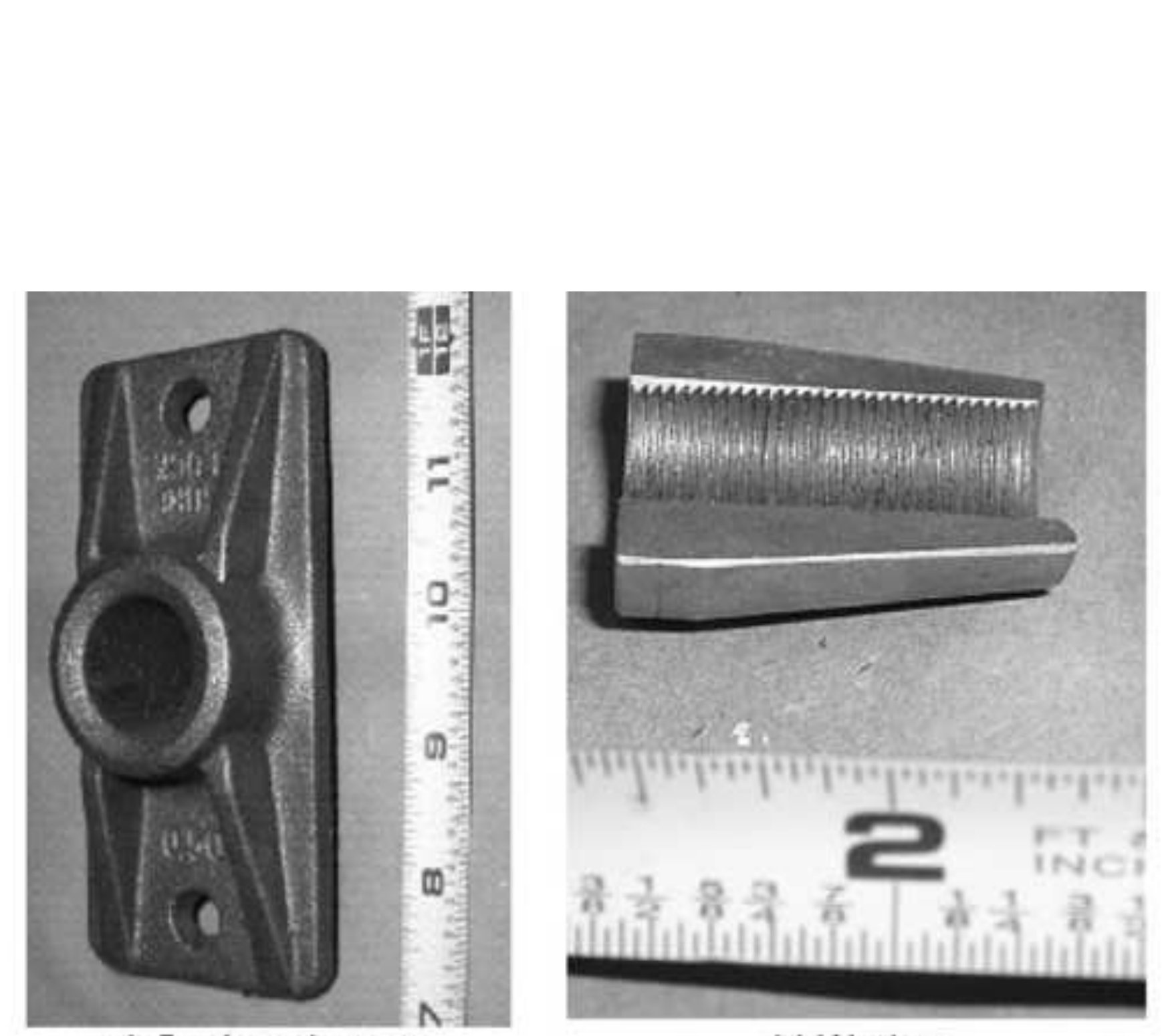

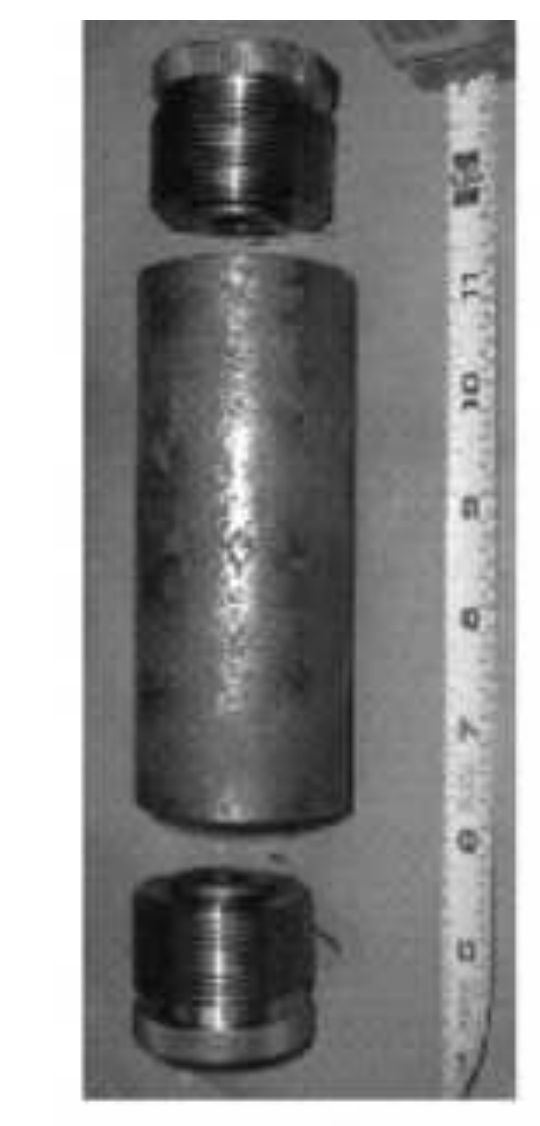

c) Coupler

\begin{abstract}
.
\end{abstract}

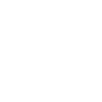

.




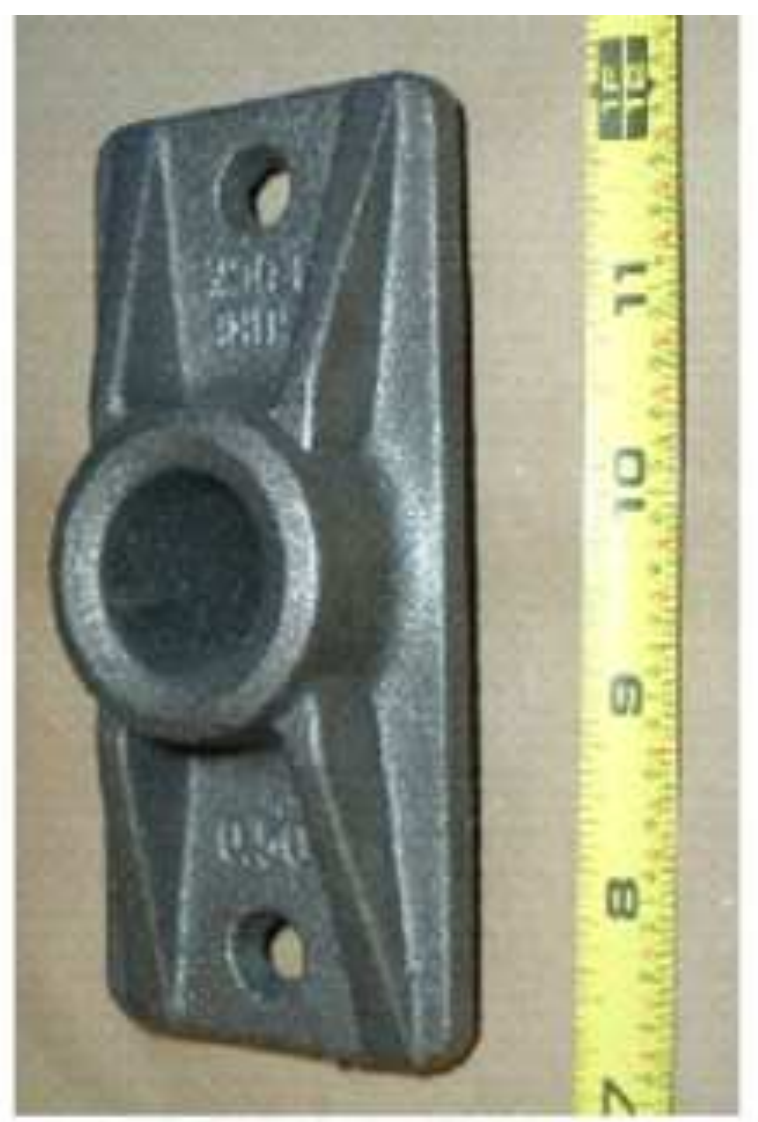

a) Cast anchorage

a) Cast anchorage

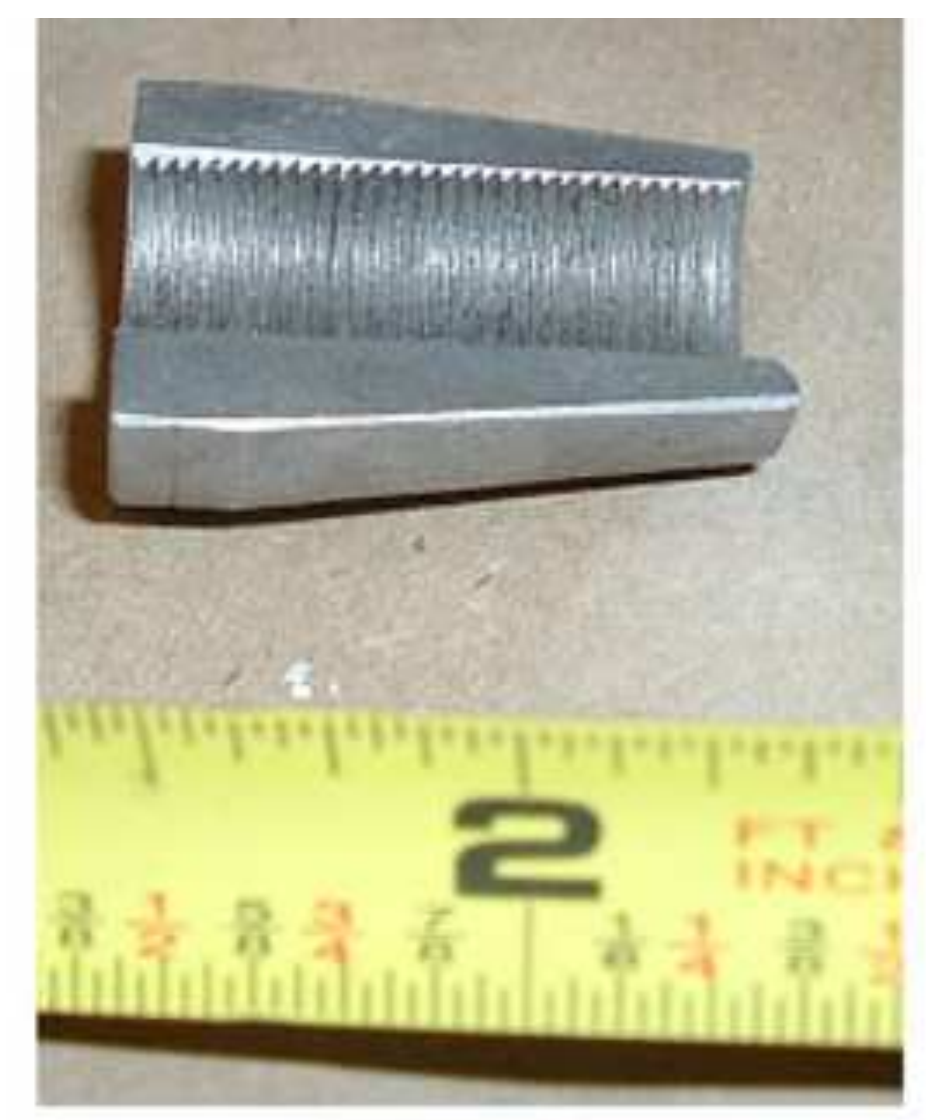

b) Wedge

b) Wedge

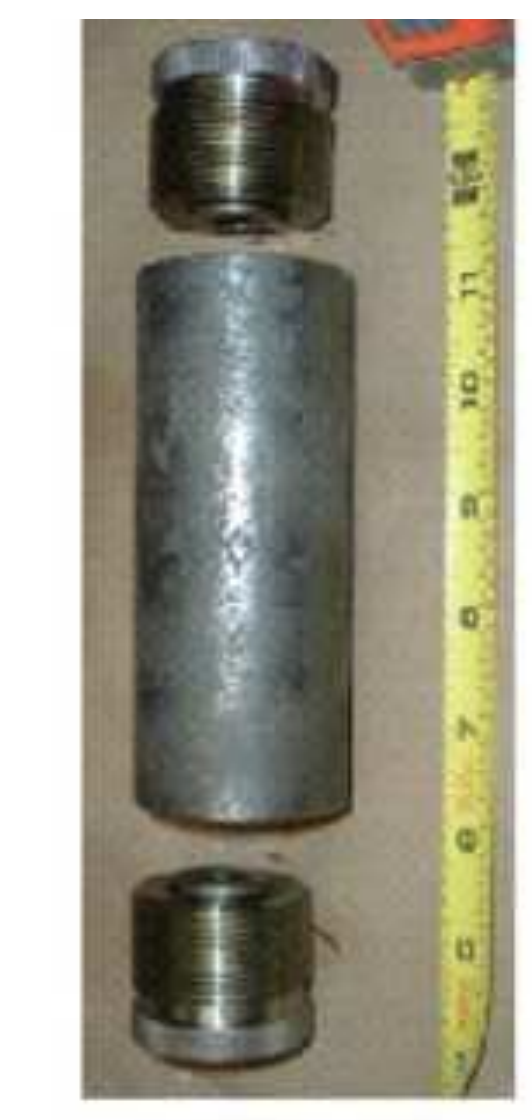

c) Coupler

c) Coupler

. 


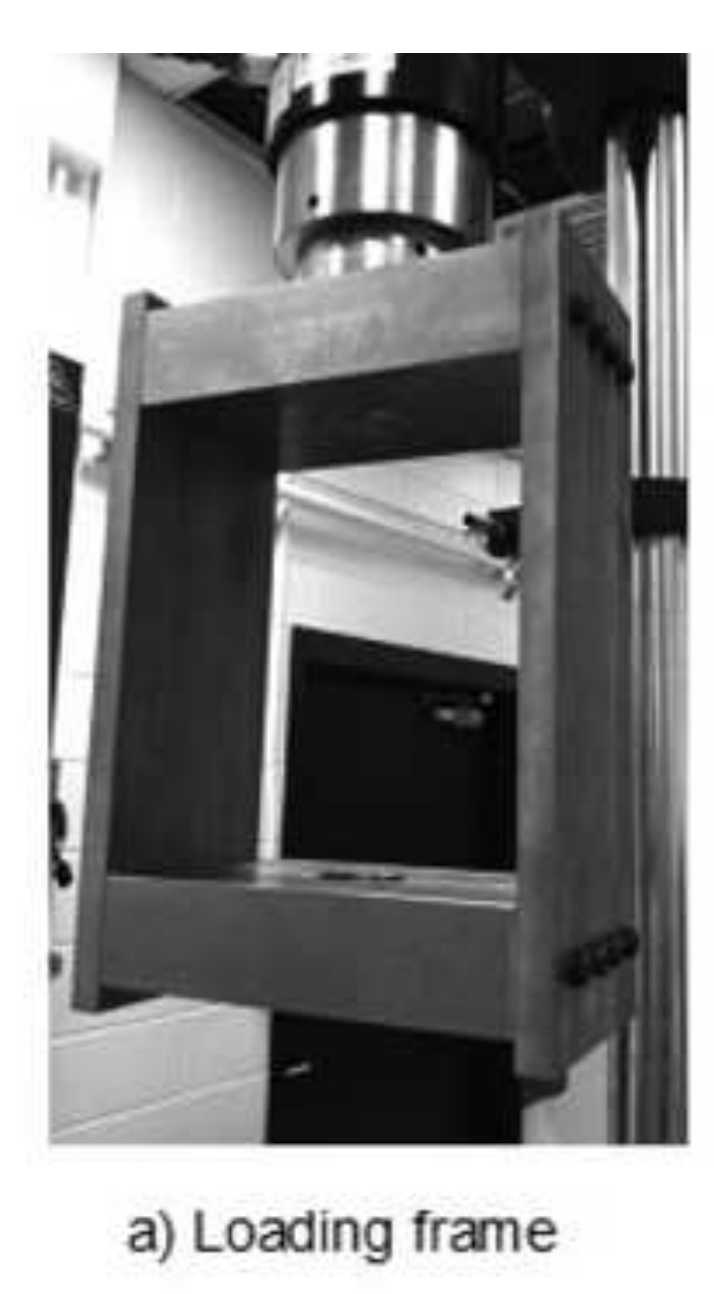

a) Loading frame

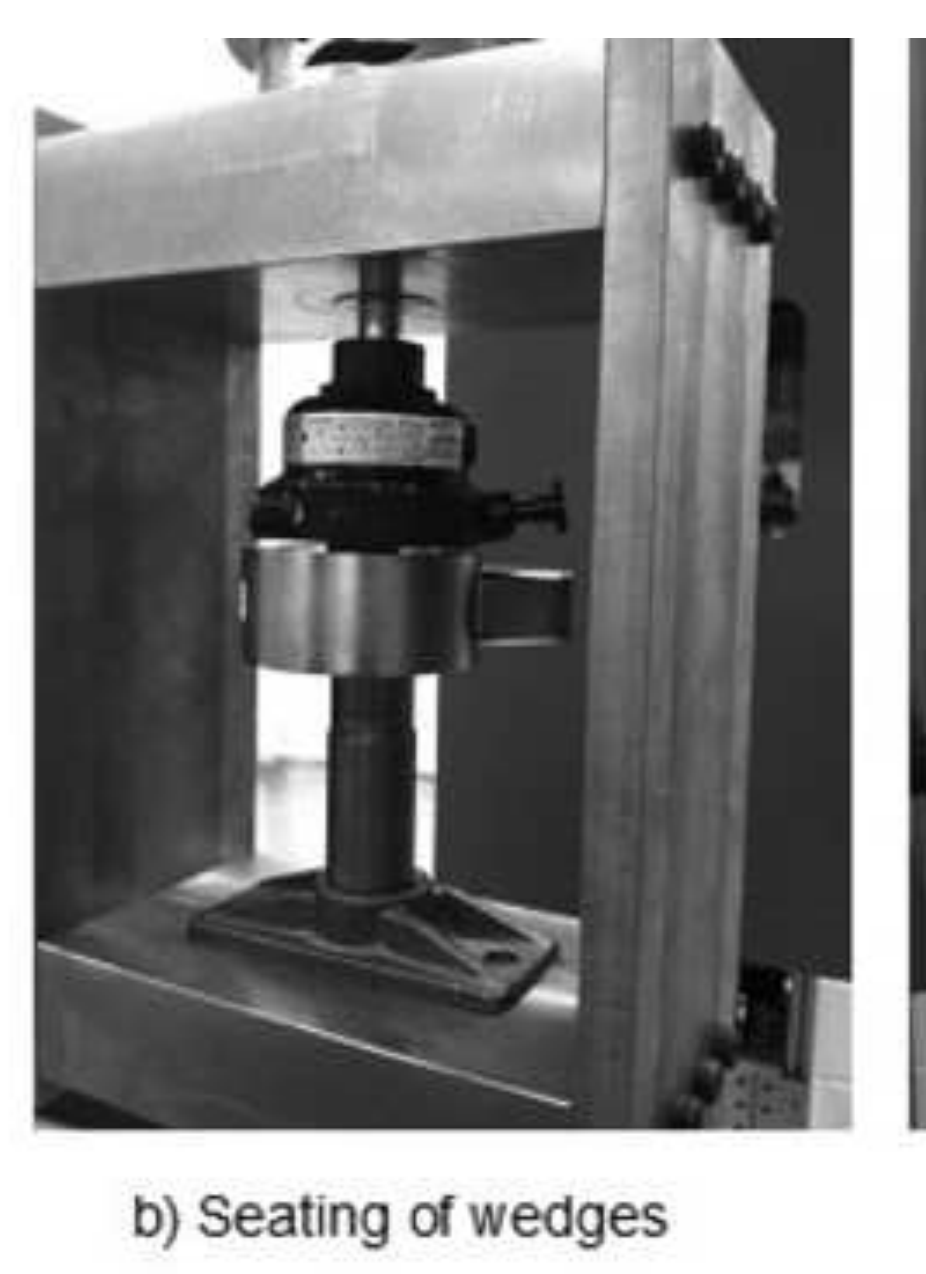

b) Seating of wedges

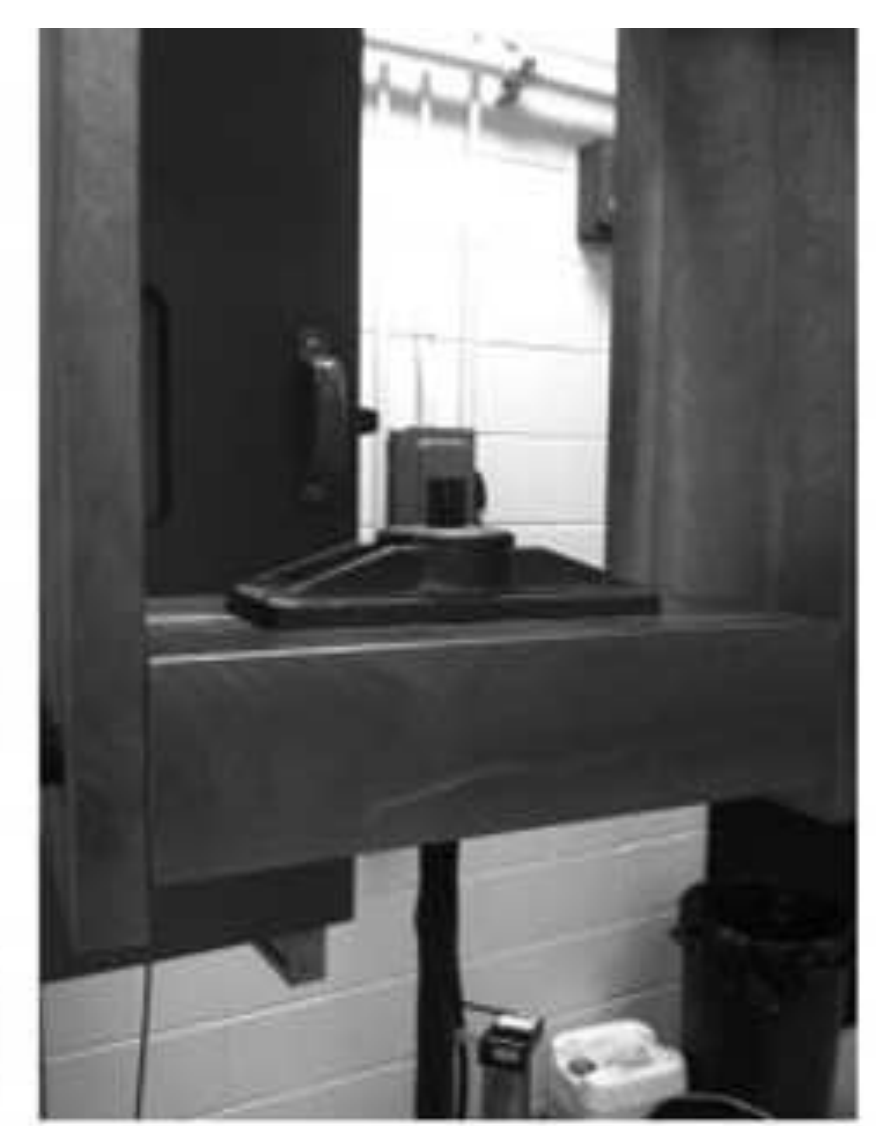

c) Anchorage after seating

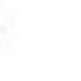




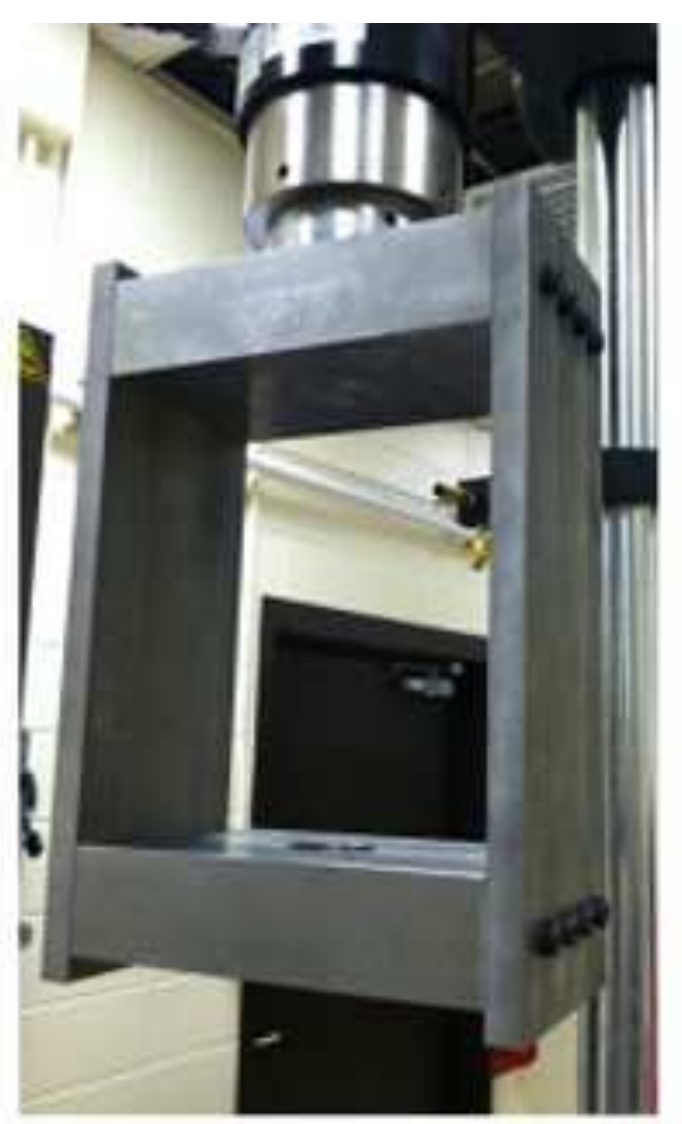

a) Loading frame

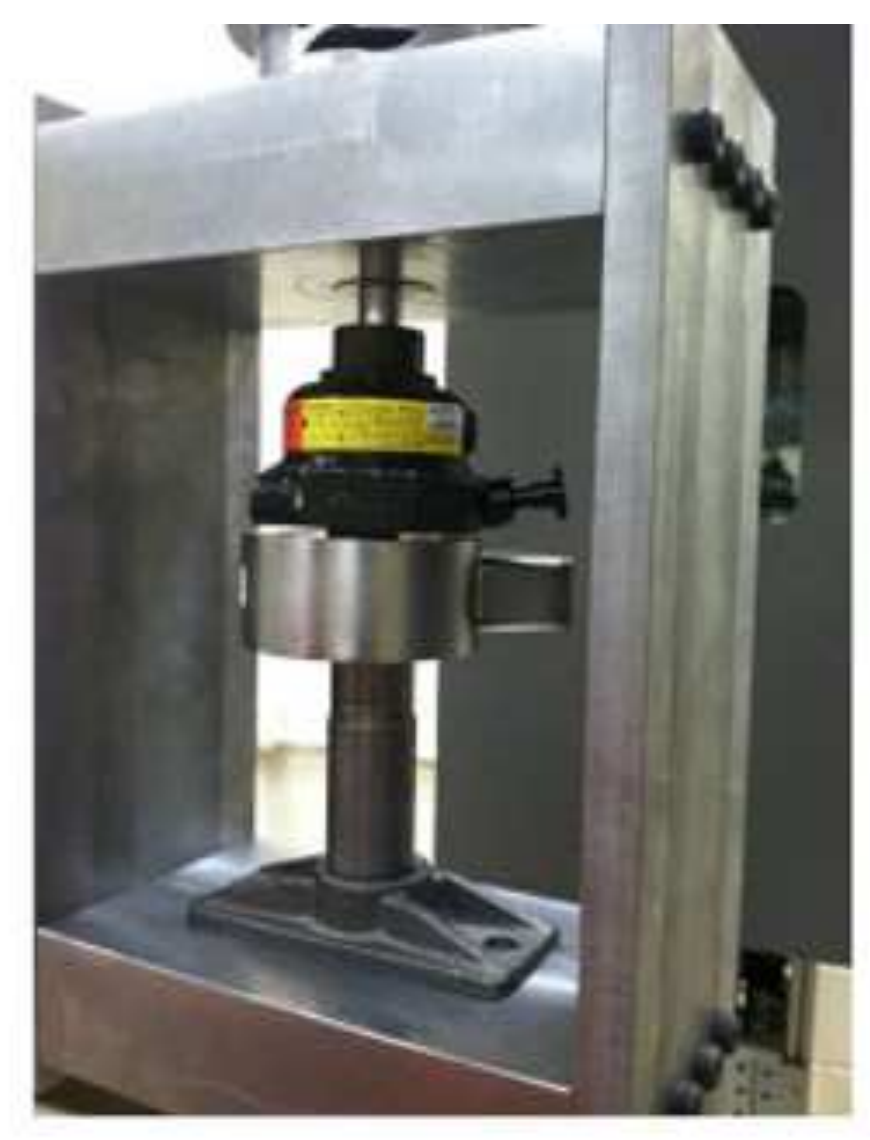

b) Seating of wedges

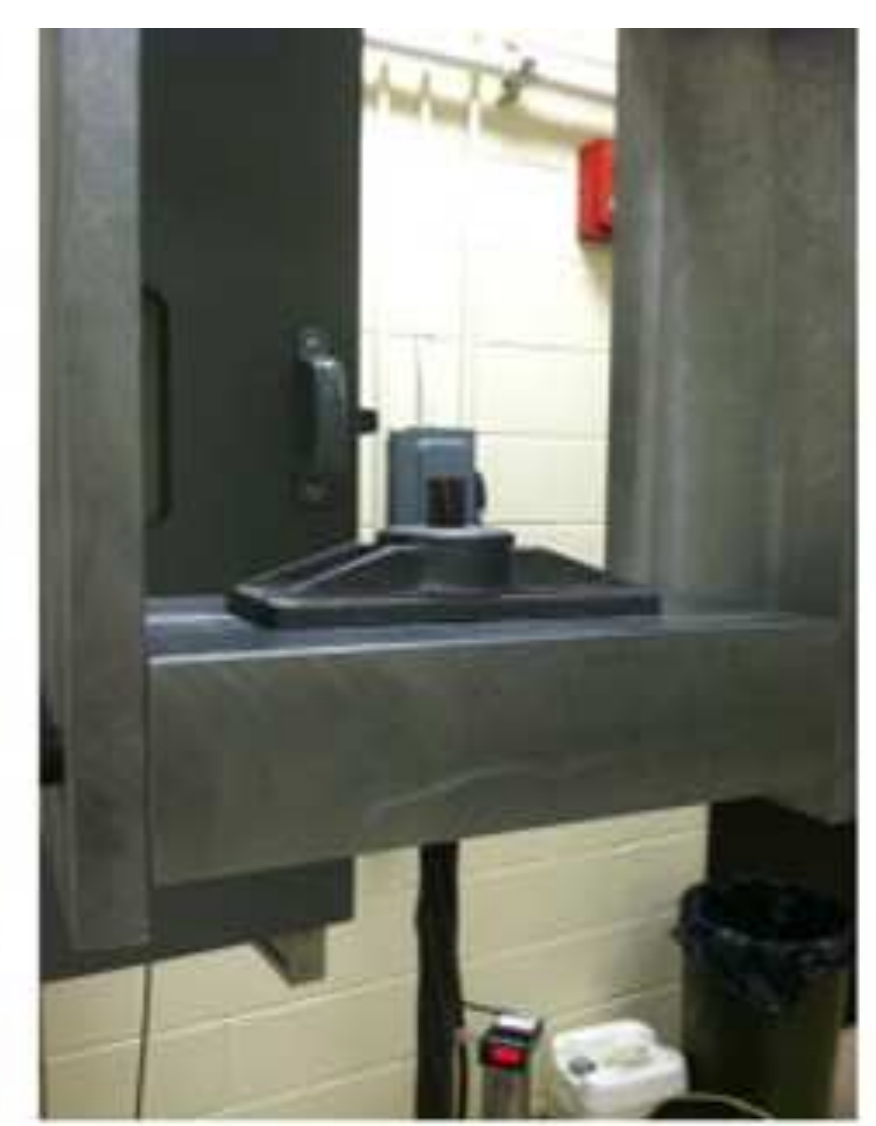

c) Anchorage after seating 


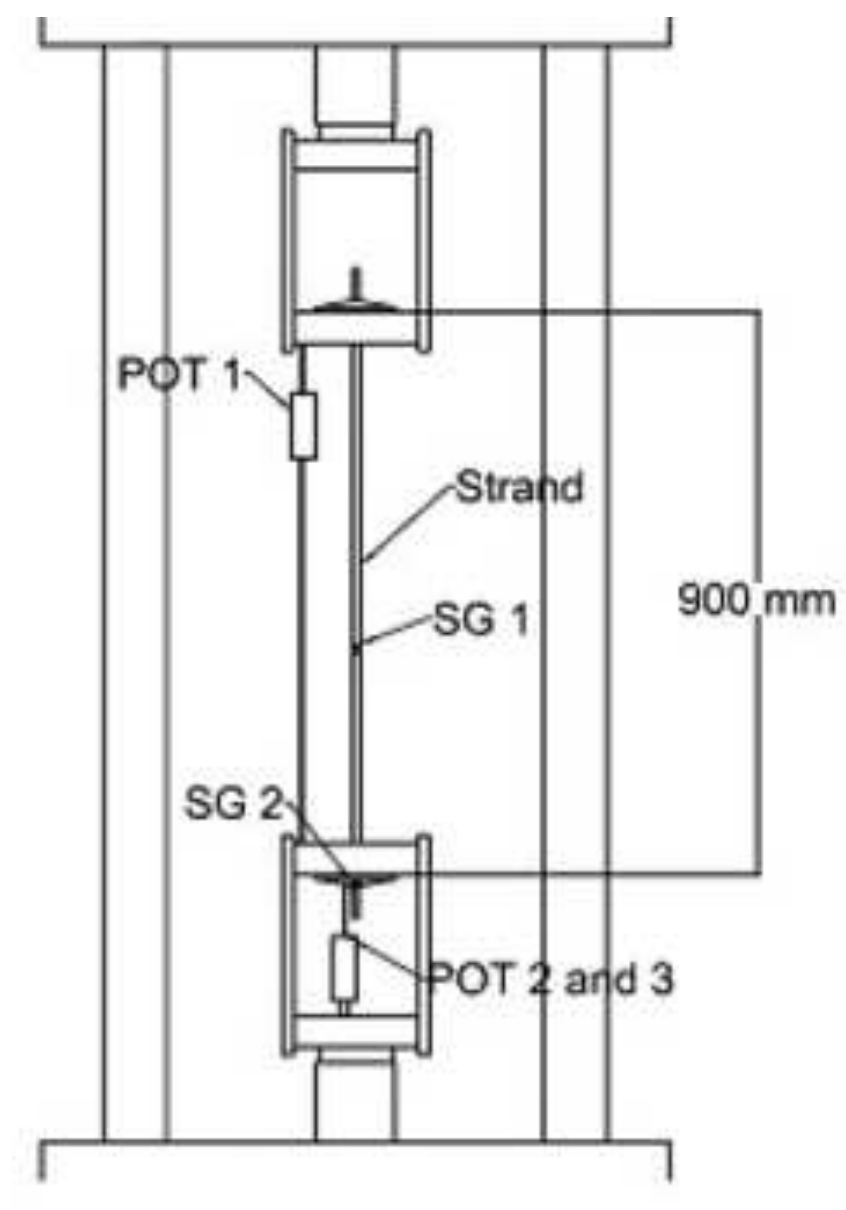

a) Strain Gage Instrumentation

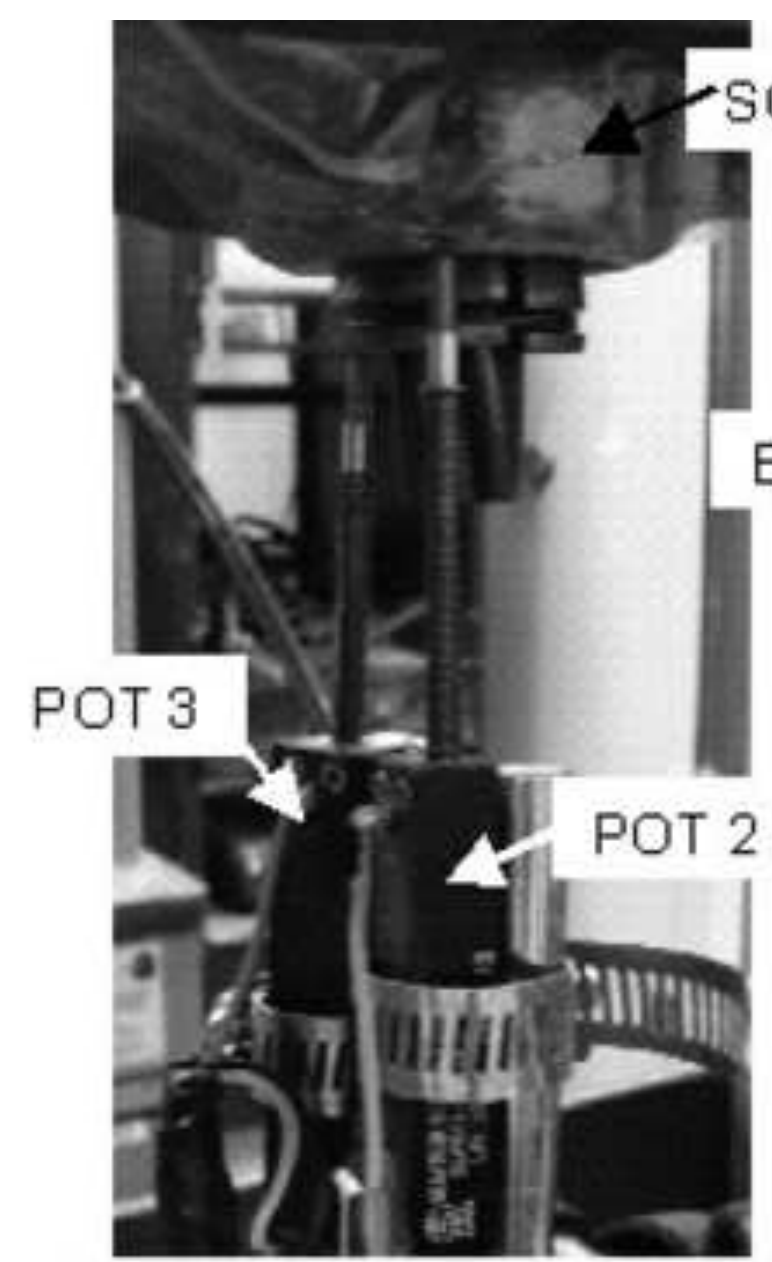

b) Monitoring of anchor and wedge movement

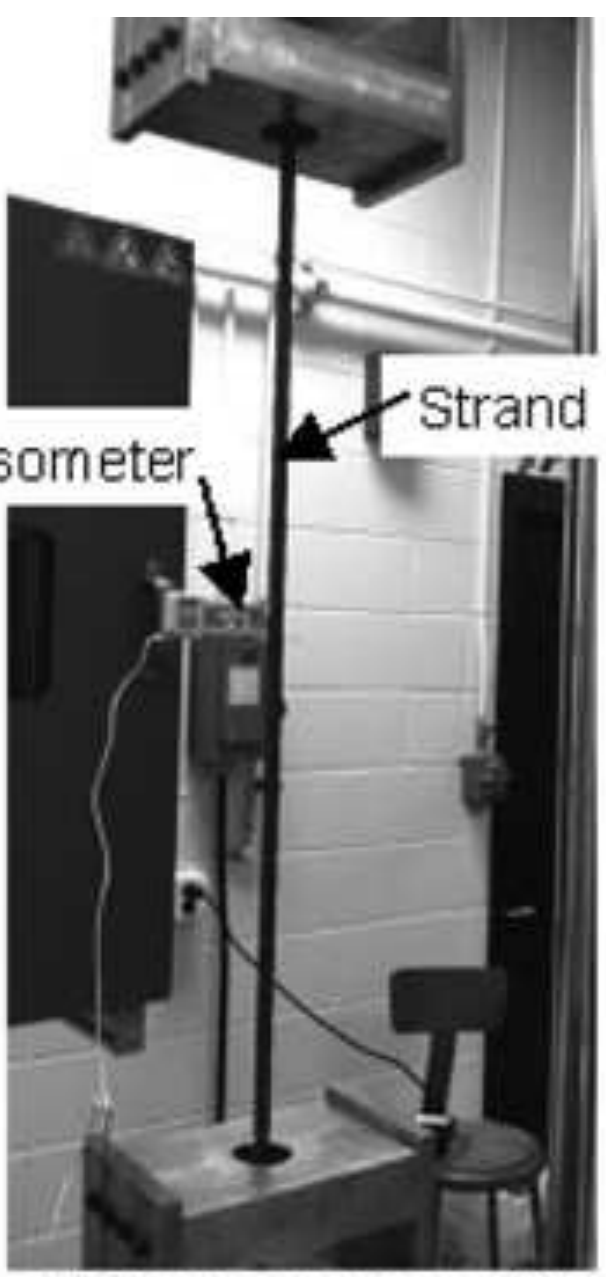

c) Extensometer setup 


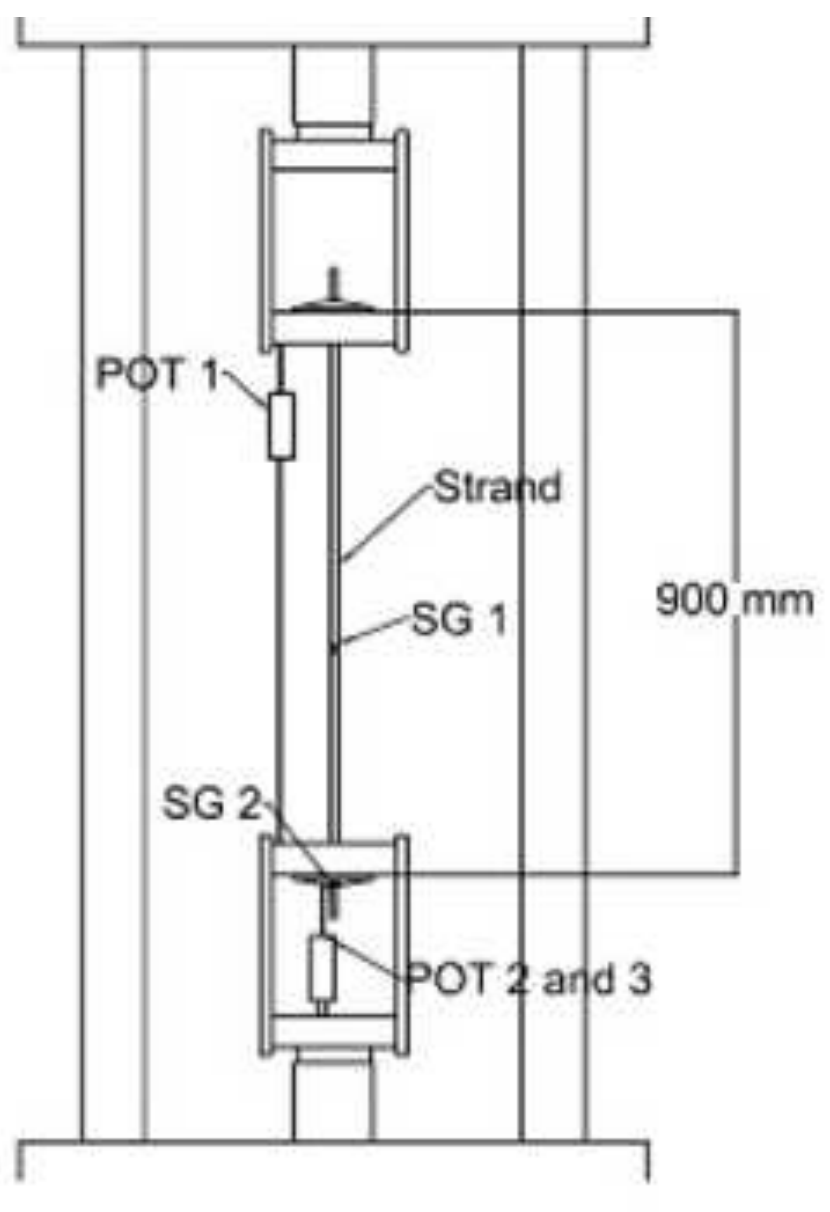

a) Strain Gage Instrumentation b) Monitoring of anchor and wedge movement

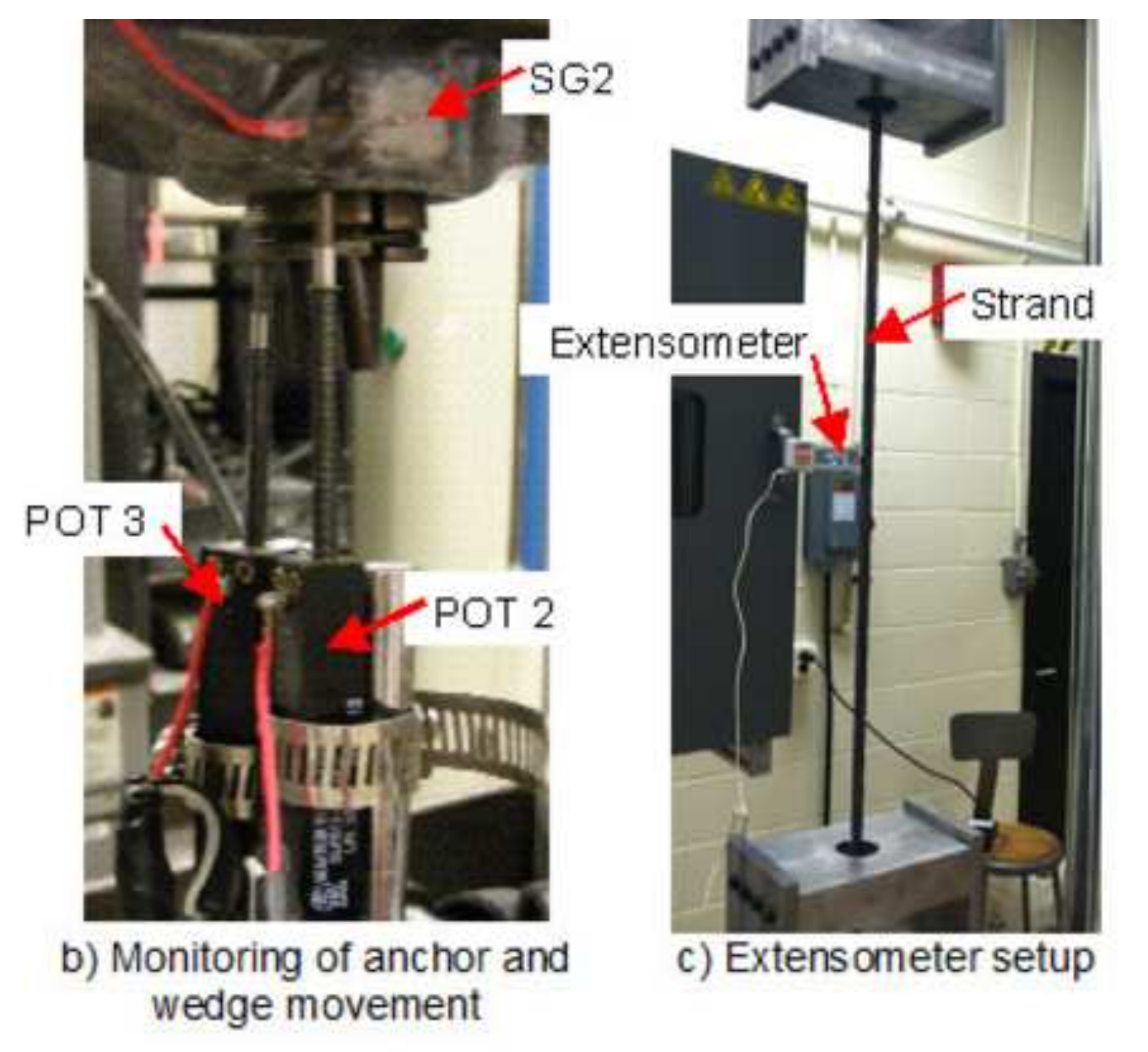

c) Extensometer setup

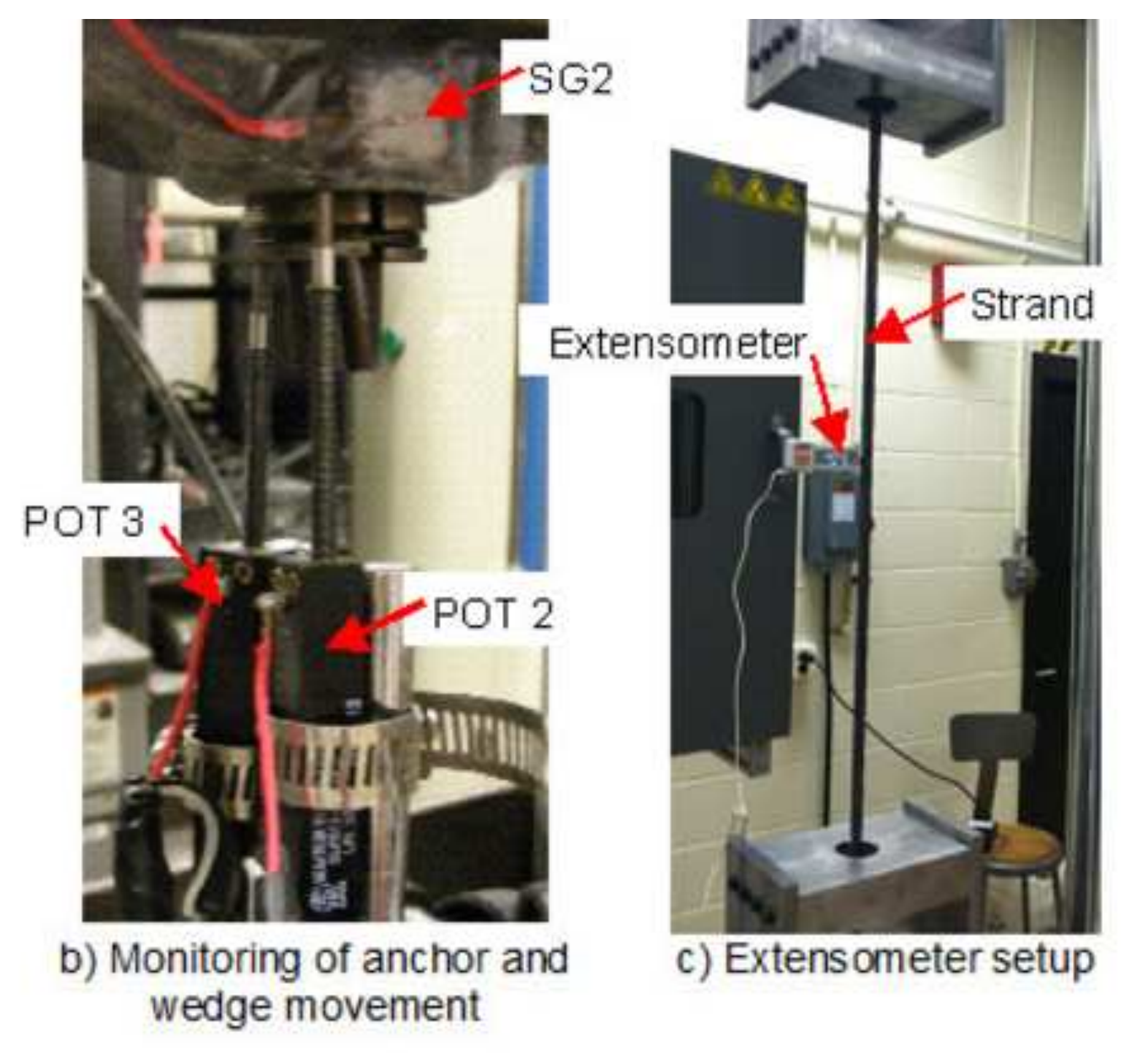

$$
\text { (n) }
$$

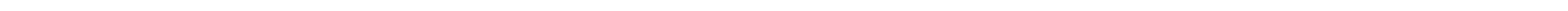




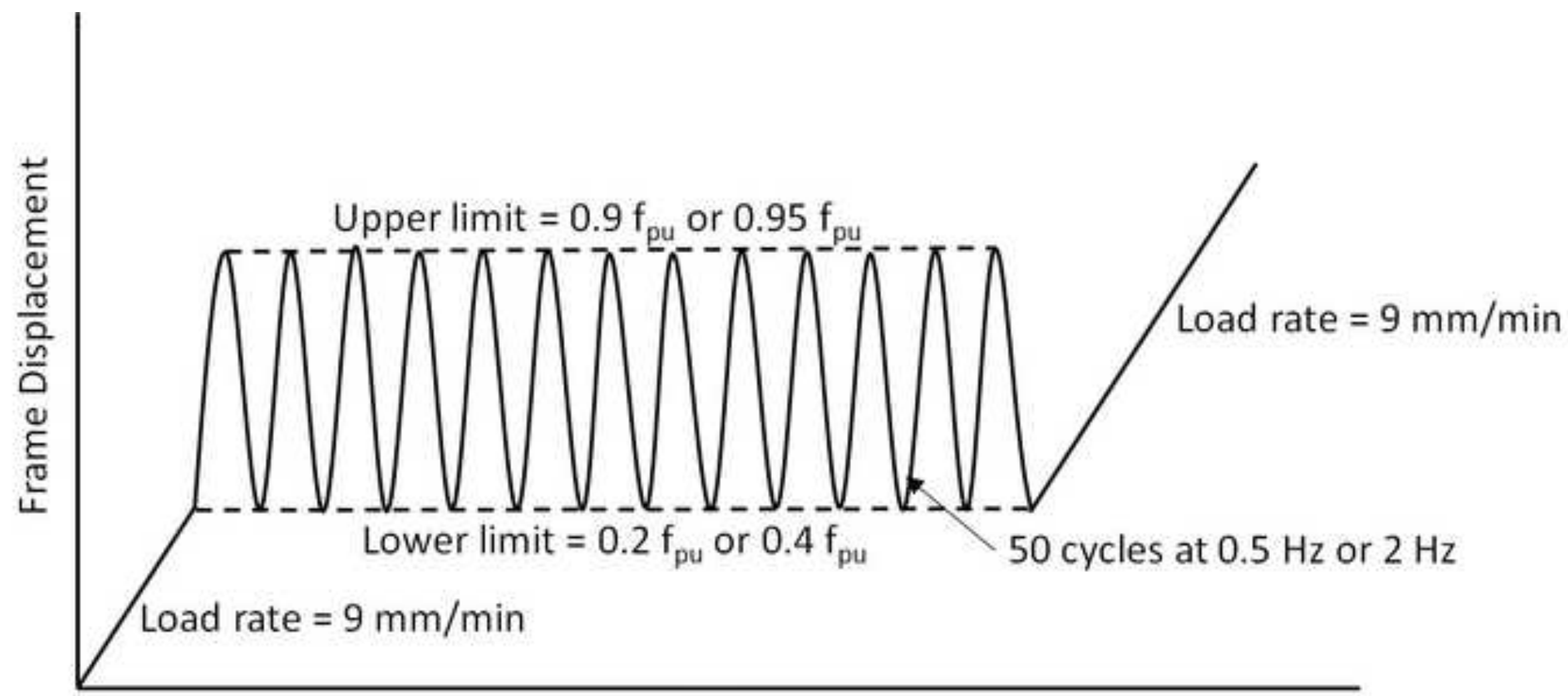

Time 


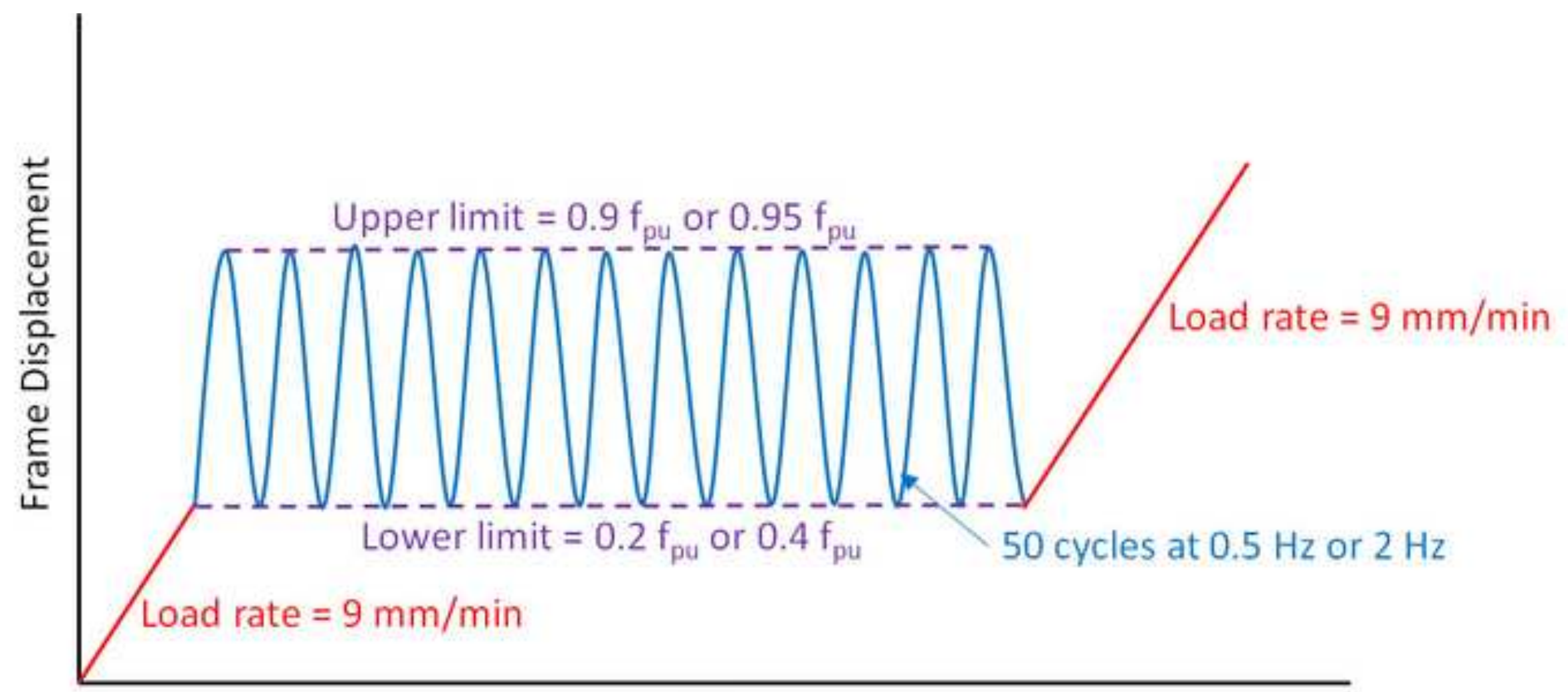

Time 


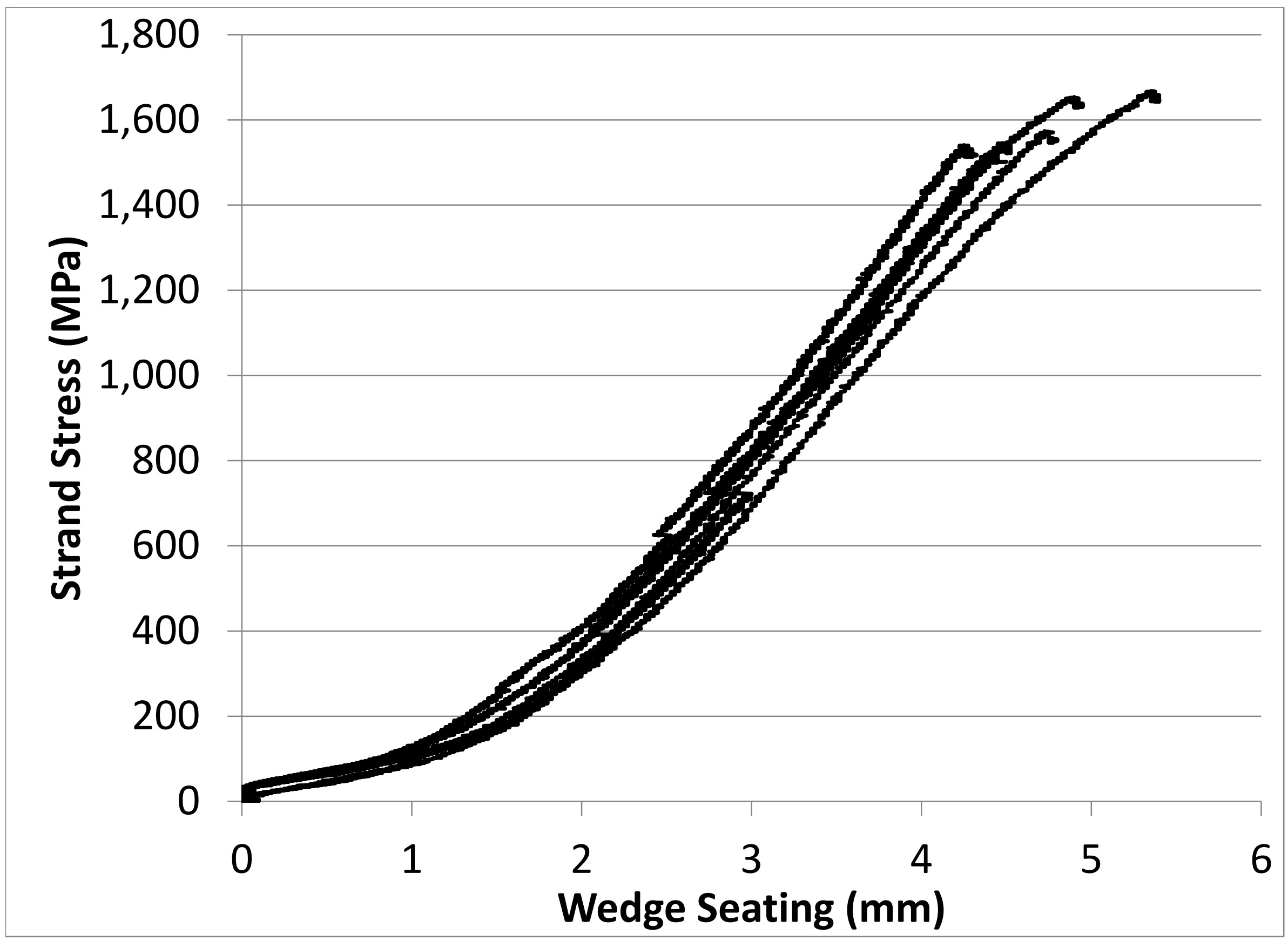




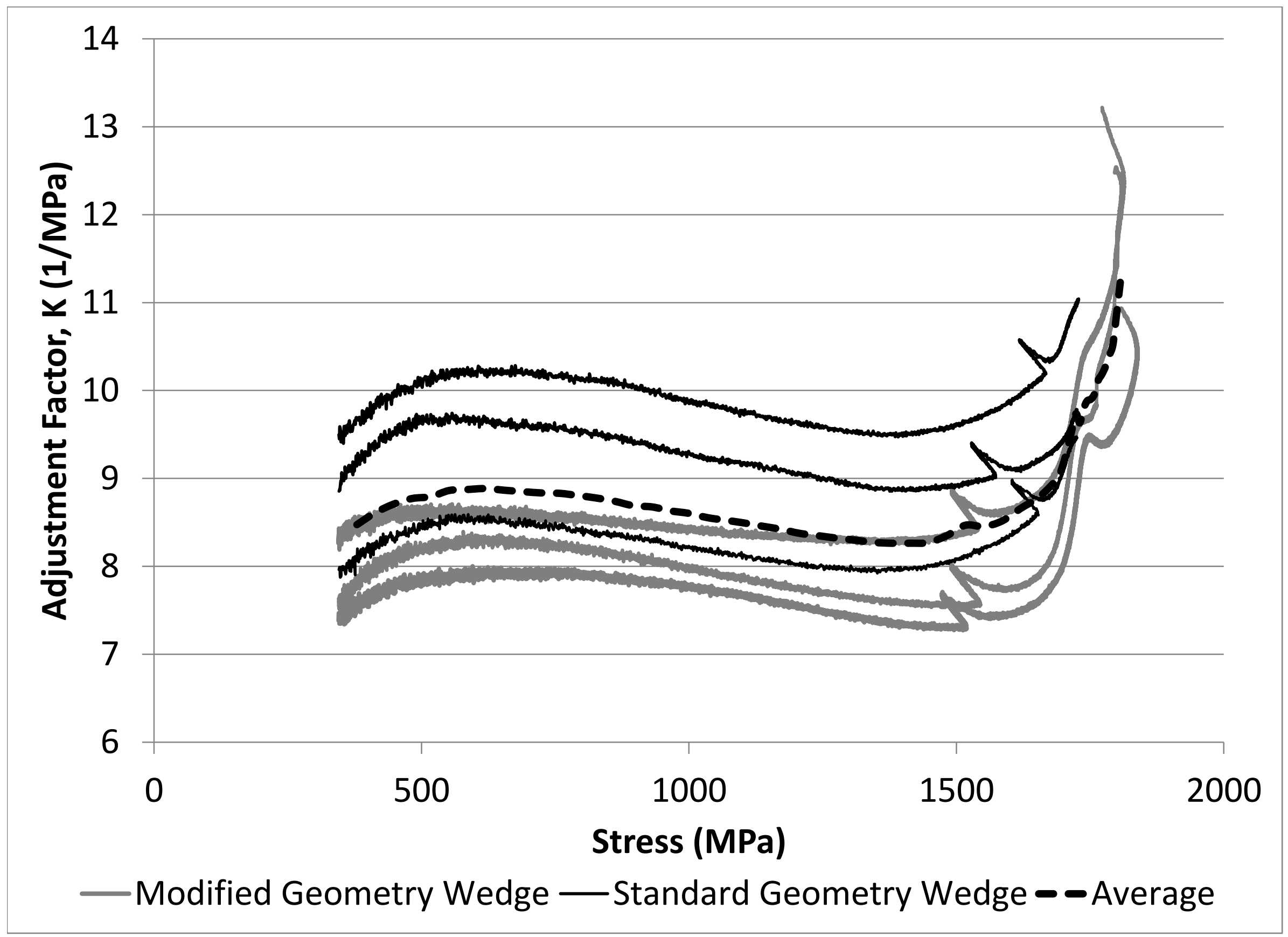




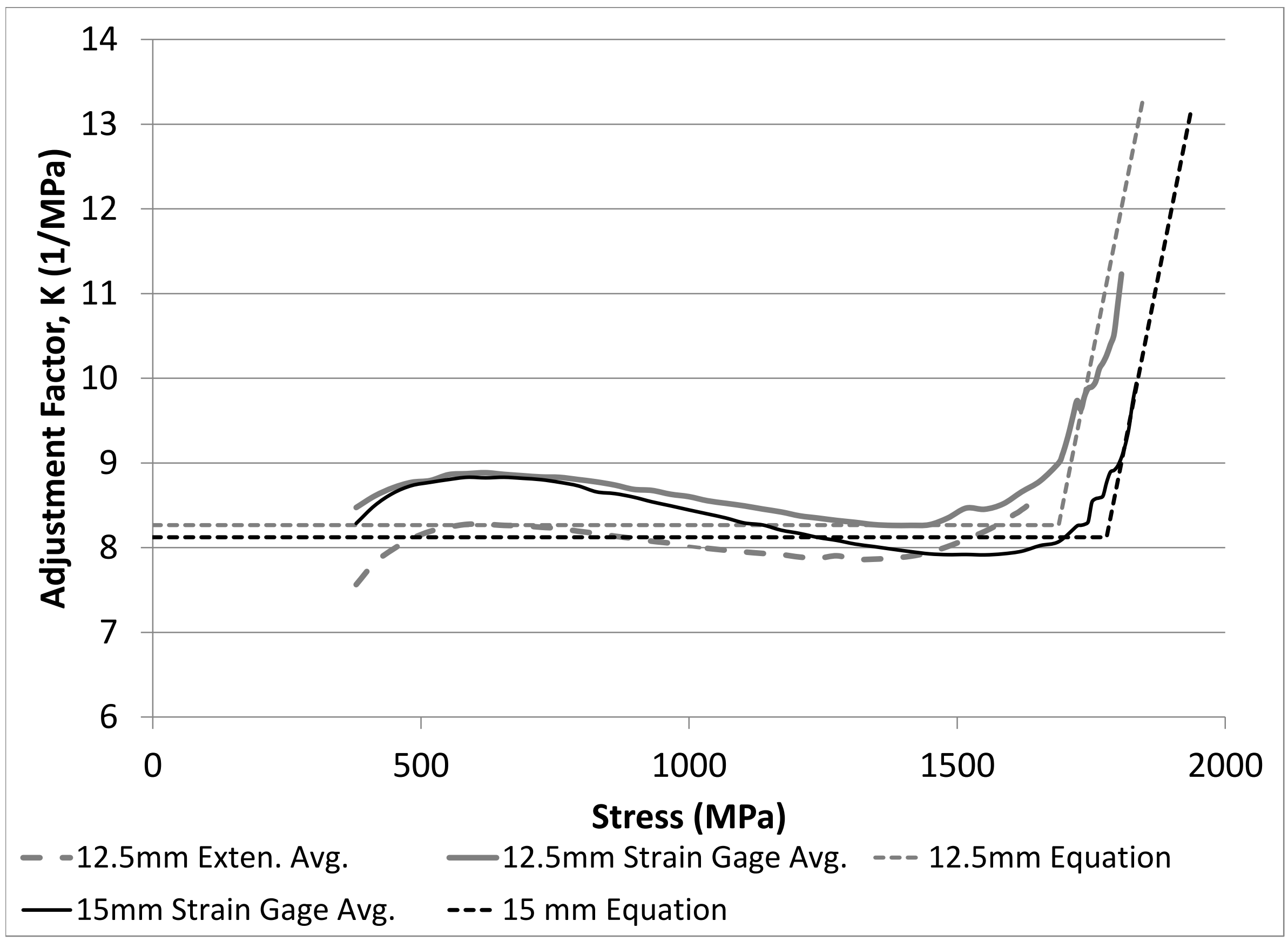




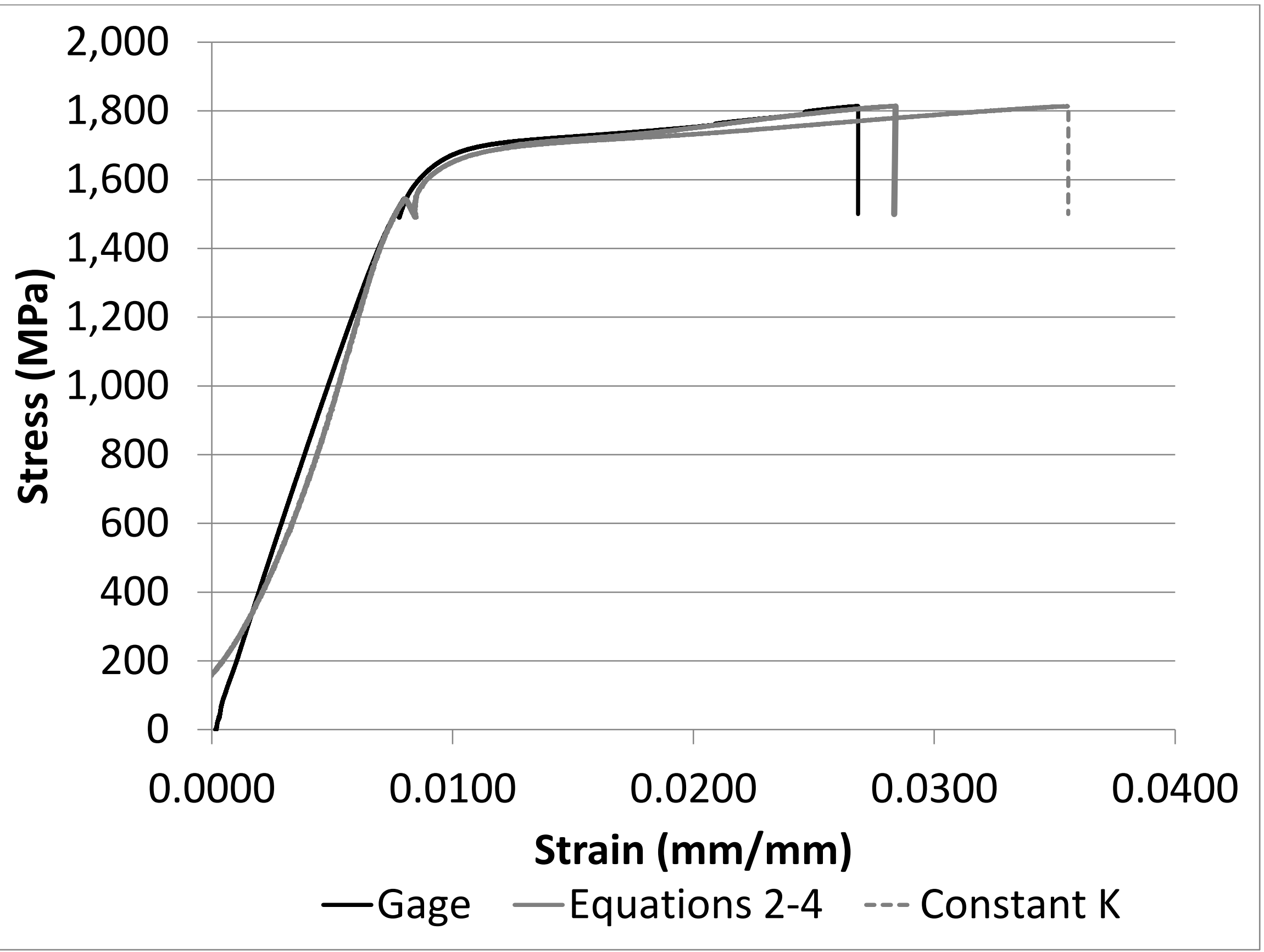




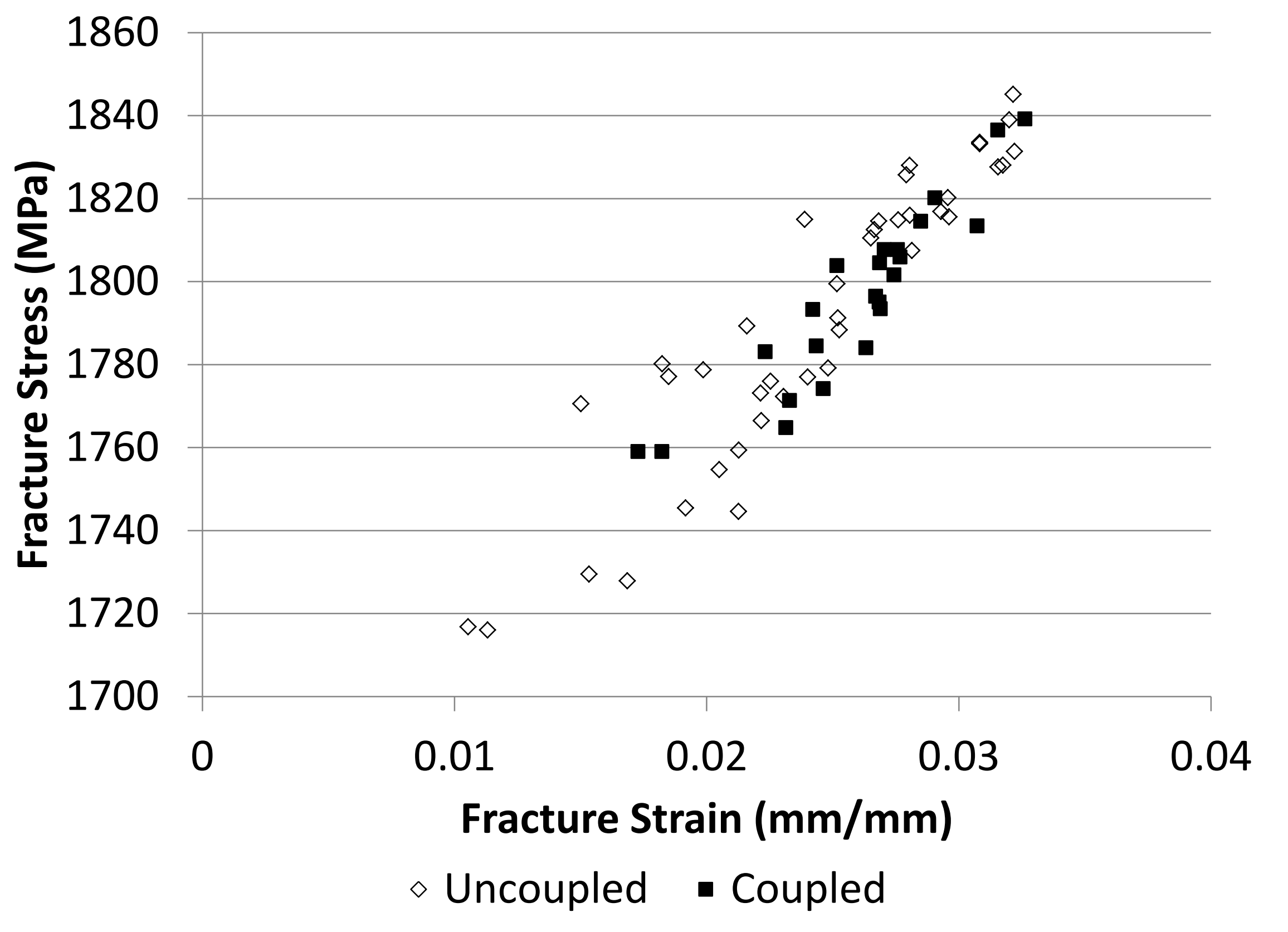




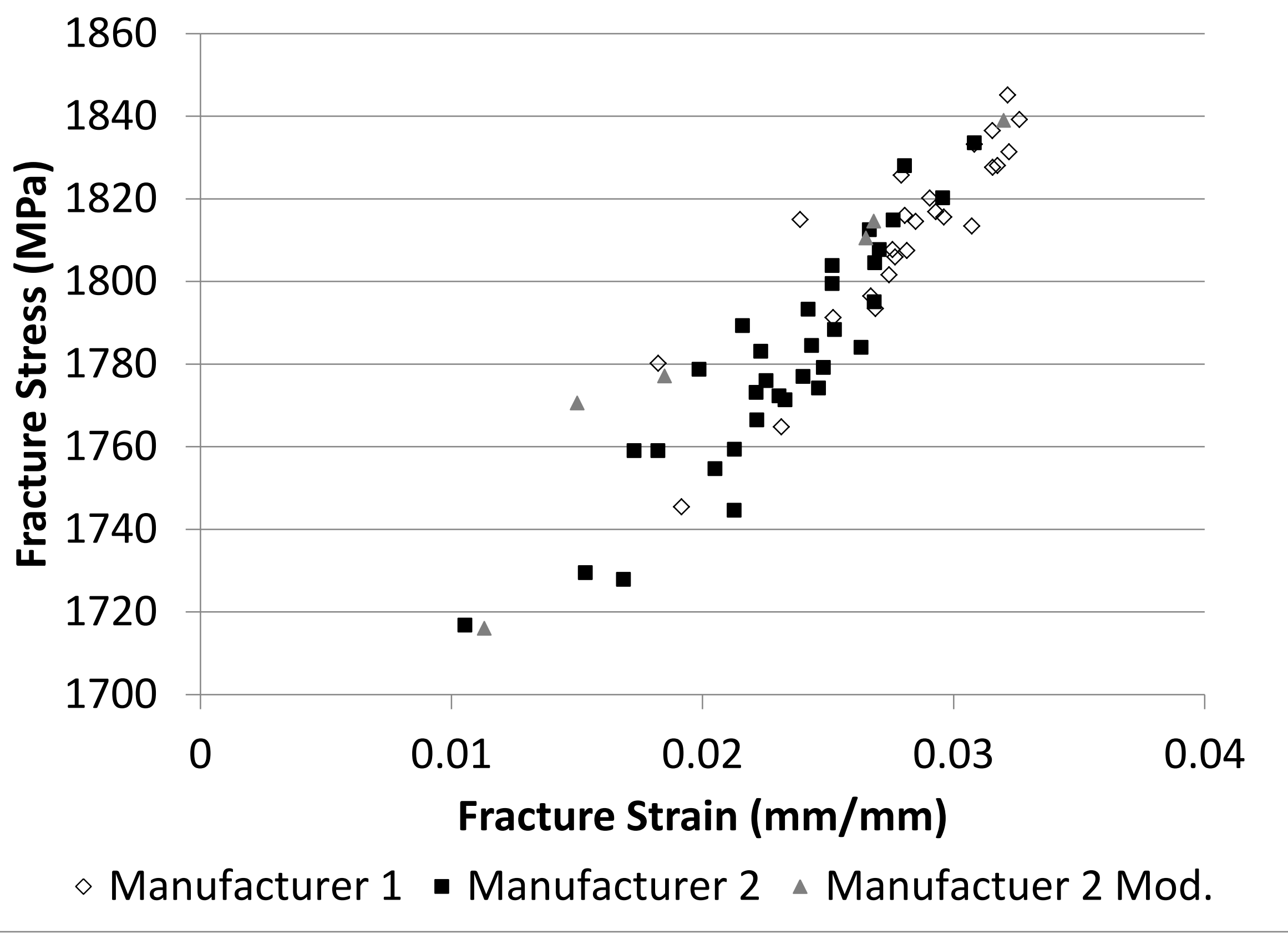




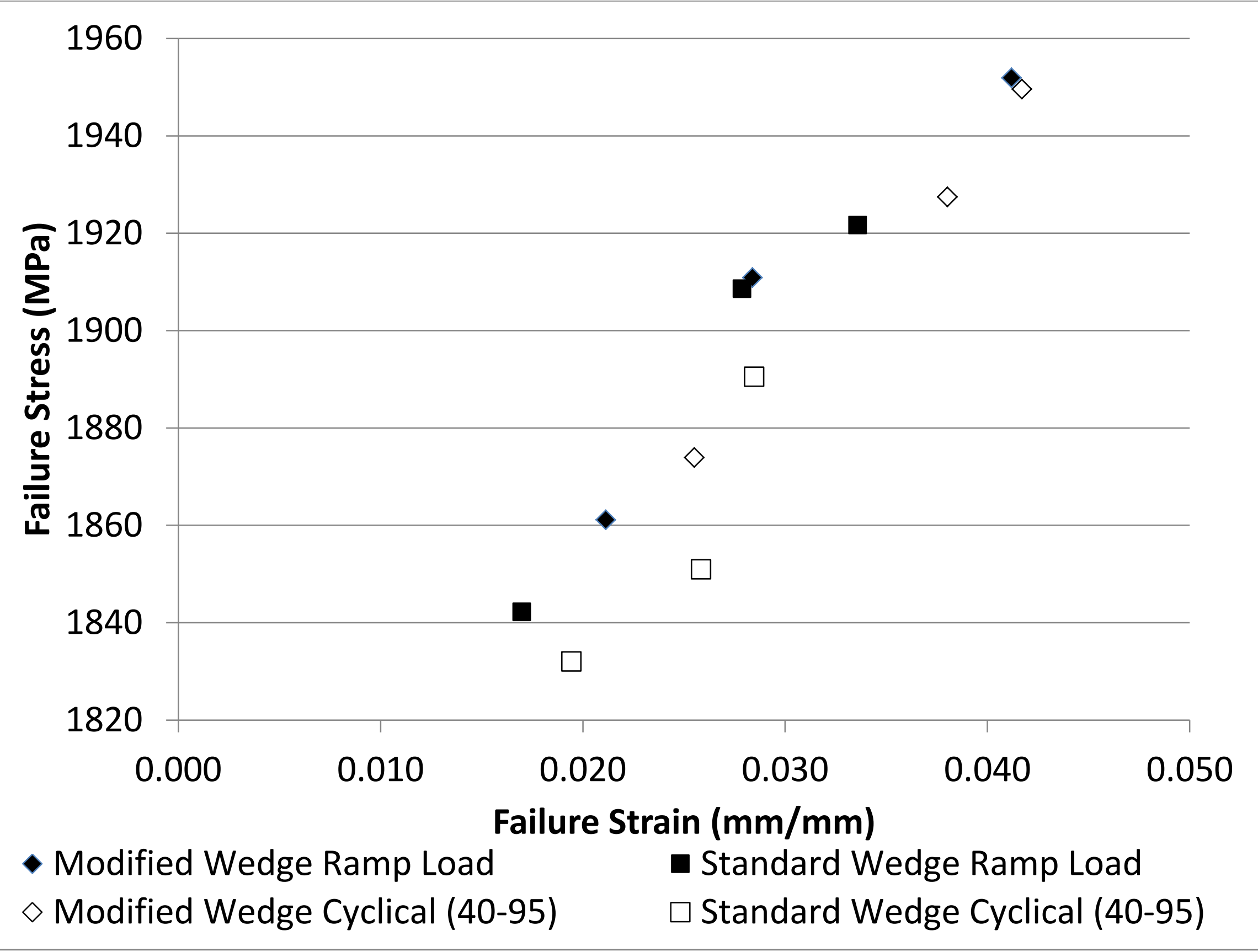




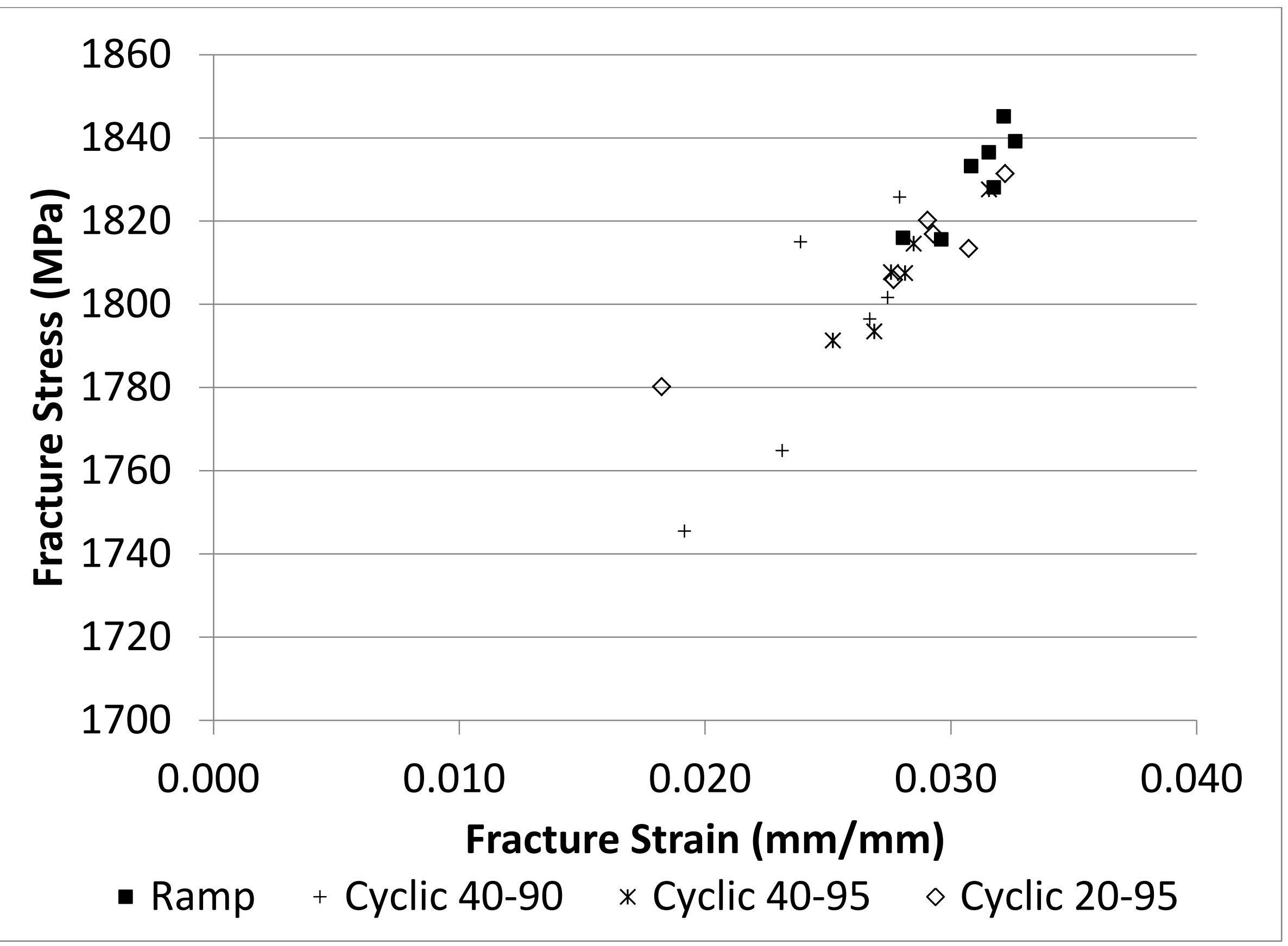




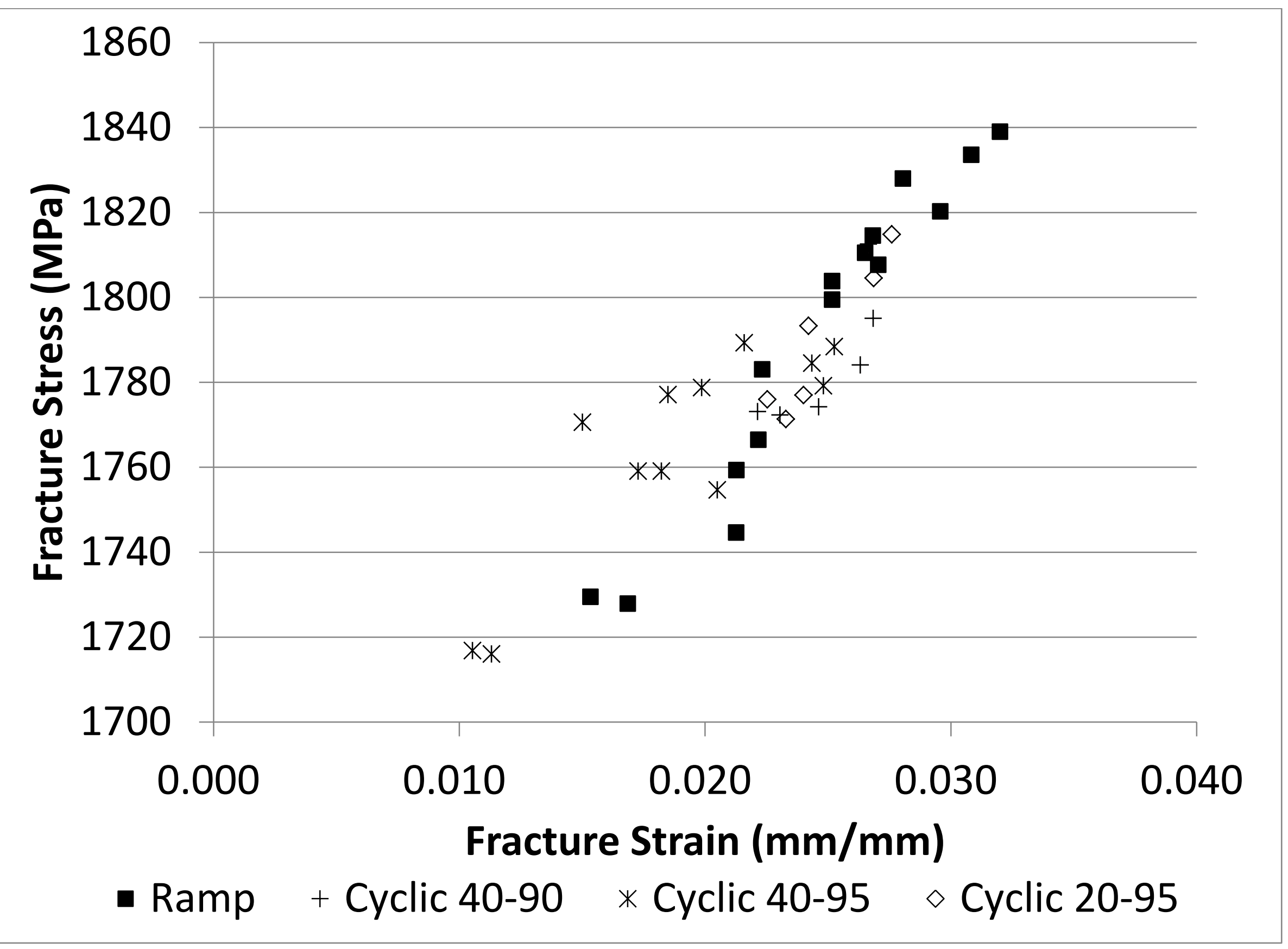




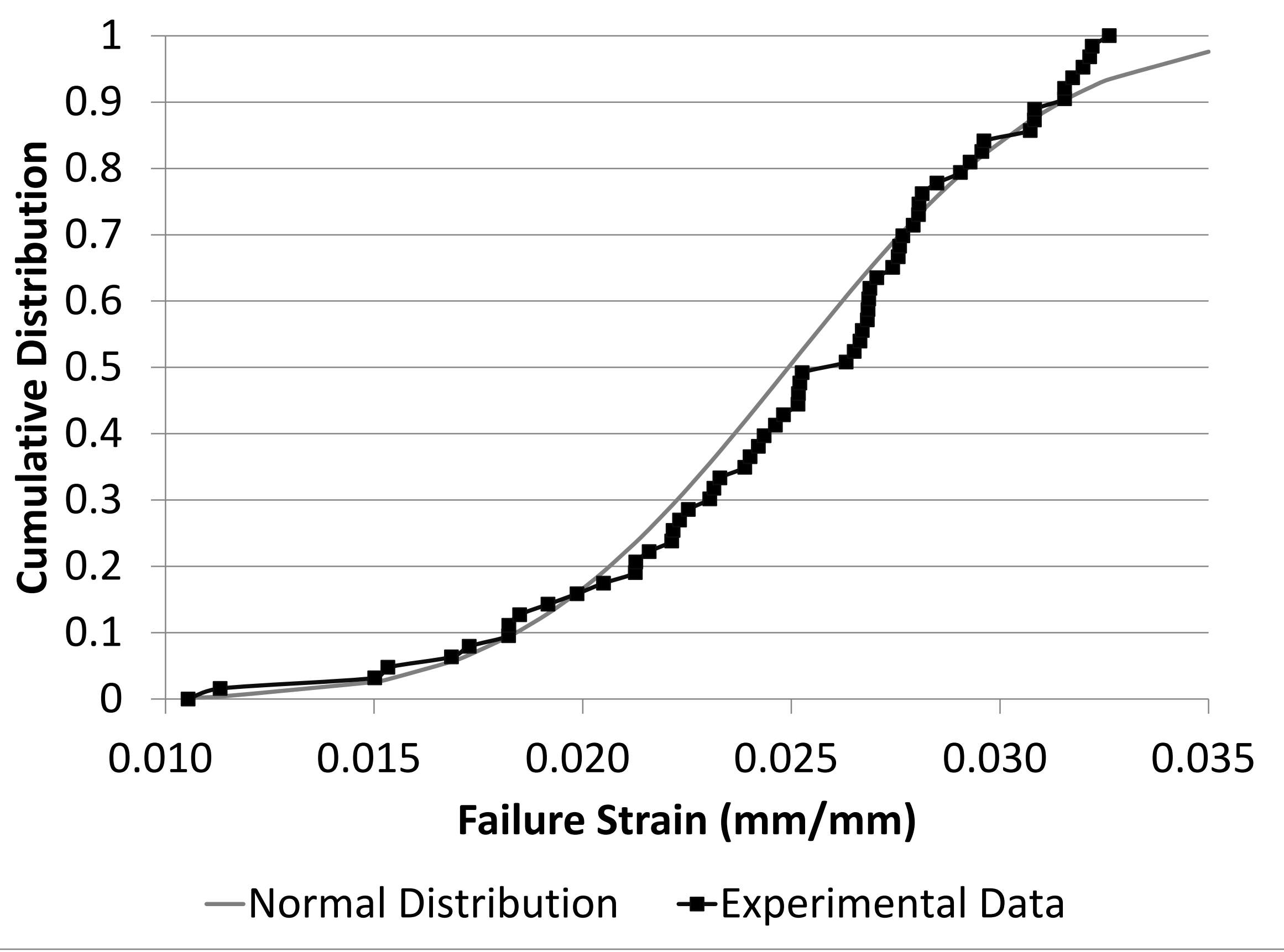

